\title{
Lane-change path planning and control method for self-driving articulated trucks
}

\author{
Tao Peng \\ School of Electrical and Information Engineering, Tianjin University, Tianjin, China; Joint Laboratory for Internet of Vehicles, \\ Ministry of Education - China Mobile Communications Corporation, Beijing, China and China Automotive Technology \\ and Research Center Co. Ltd., Tianjin, China \\ Xingliang Liu and Rui Fang \\ China Automotive Technology and Research Center Co., Ltd., Tianjin, China \\ Ronghui Zhang \\ Guangdong Key Laboratory of Intelligent Transportation System, School of Intelligent Systems Engineering, \\ Sun Yat-sen University, Zhuhai, China \\ Yanwei Pang \\ School of Electrical and Information Engineering, Tianjin University, Tianjin, China \\ Tao Wang \\ Tianjin University of Technology and Education, Tianjin, China, and \\ Yike Tong \\ Zhejiang University of Technology, Hangzhou, China
}

\begin{abstract}
Purpose - This study aims to develop an automatic lane-change mechanism on highways for self-driving articulated trucks to improve traffic safety. Design/methodology/approach - The authors proposed a novel safety lane-change path planning and tracking control method for articulated vehicles. A double-Gaussian distribution was introduced to deduce the lane-change trajectories of tractor and trailer coupling characteristics of intelligent vehicles and roads. With different steering and braking maneuvers, minimum safe distances were modeled and calculated. Considering safety and ergonomics, the authors invested multilevel self-driving modes that serve as the basis of decision-making for vehicle lane-change. Furthermore, a combined controller was designed by feedback linearization and single-point preview optimization to ensure the path tracking and robust stability. Specialized hardware in the loop simulation platform was built to verify the effectiveness of the designed method.

Findings - The numerical simulation results demonstrated the path-planning model feasibility and controller-combined decision mechanism effectiveness to self-driving trucks. The proposed trajectory model could provide safety lane-change path planning, and the designed controller could ensure good tracking and robust stability for the closed-loop nonlinear system.

Originality/value - This is a fundamental research of intelligent local path planning and automatic control for articulated vehicles. There are two main contributions: the first is a more quantifiable trajectory model for self-driving articulated vehicles, which provides the opportunity to adapt vehicle and scene changes. The second involves designing a feedback linearization controller, combined with a multi-objective decision-making mode, to improve the comprehensive performance of intelligent vehicles. This study provides a valuable reference to develop advanced driving assistant system and intelligent control systems for self-driving articulated vehicles.
\end{abstract}

Keywords Feedback linearization, Combined controller, Double Gaussian distribution, Lane-change path planning, Preview optimization, Self-driving articulated truck

Paper type Research paper

\section{Introduction}

Reliable research has shown that drivers' faults are accountable for more than $70 \%$ of traffic incidents, so that

The current issue and full text archive of this journal is available on Emerald Insight at: https://www.emerald.com/insight/2399-9802.htm

Journal of Intelligent and Connected Vehicles $3 / 2(2020) 49-66$

Emerald Publishing Limited [ISSN 2399-9802] [DOI 10.1108/JICV-10-2019-0013]
(C) Tao Peng, Xingliang Liu, Rui Fang, Ronghui Zhang, Yanwei Pang, Tao Wang and Yike Tong. Published in foumal of Intelligent and Connected Vehicles. Published by Emerald Publishing Limited. This article is published under the Creative Commons Attribution (CC BY 4.0) licence. Anyone may reproduce, distribute, translate and create derivative works of this article (for both commercial and non-commercial purposes), subject to full attribution to the original publication and authors. The full terms of this licence may be seen at http://creativecommons.org/licences/by/4.0/legalcode

Received 29 October 2019

Revised 8 February 2020

18 April 2020

11 June 2020

Accepted 29 June 2020 
most traffic accidents could be avoided (Jonathan et al., 2018). Thus, countries have formulated strict laws and regulations to manage drivers. For example, China's public security administrative departments have implemented special management for drunk driving and continuously increased punishment since 2009. However, driver-related traffic accidents are still serious these years because aspects such as driver fatigue and inattention are challenging to regulate. Because of the fatigue and distraction of drivers, truck drivers have more enormous challenges for high-load and continuous driving and fatal traffic accidents frequently occur. Data from China's Highway Traffic Safety Administration show that the number of traffic accidents and deaths caused by commercial trucks has increased by $5.8 \%$ and $6.6 \%$ (PSTMD, 2017). Advanced driving assistant systems (ADAS) and self-driving vehicles could decrease traffic accidents. Thus, these vehicles are programmed to mimic human drivers to perform simple driving tasks on the road. Low-level self-driving trucks that use onboard sensors, signal processing, driving control and actuators have already been used in some closed areas, such as ports and mines. They have also been tested on highways by Waymo, Daimler, Hyundai, TuSimple and so on (Litman, 2015). Compared with the following behavior, the lane-change behavior considers more factors and the decision-making process is more complex and challenging to maneuver, so it is prone to traffic accidents while lane changing. Thus, path planning for lane-change and tracking controller for self-driving articulated trucks on highways needs to developed.

A feasible local path planning must be carried out and trajectories from a host lane to a goal lane in time are generated to ensure safe lane-change for a self-driving vehicle. The determined tracking trajectory by an intelligent decision must satisfy driving stability, anticollision with surrounding vehicles and even ride comfort. Many researchers have focused on these issues by heuristic, virtual electric field and geometric approaches. For the heuristic approach, artificial intelligence is one of the most popular ways, involving random sampling, machine learning and search-based methods. In general, based on rapidly exploring random tree, an algorithm with real-time planning is applied to operate a self-driving vehicle (Qureshi and Ayaz, 2015; Devin and Hung, 2018). Lim et al. (2018) divided the vehicle's surroundings by discrete spatiotemporal lattices and searched for an optical collision-free path along the lattice by using search methods. Some researchers also developed learning methods. Trang et al. (2017) applied neural network to predict the vehicle's future lane-change trajectory. Kumar et al. (2012) proposed a novel inference system with multiinput multi-output by adaptive neuro-fuzzy to simulate and predict the future behavior of an integrated driver-vehicle for lane change with various time delays. Heuristic methods reduce the problem complexity by simplifying environment model and it has fast search speed. However, most methods generate paths rather than trajectories, which focus more on spatial location than on time-related velocity and acceleration. Using virtual electric equations, Nurbaiti et al. (2017) used minimum electric field potential to describe a collision-free trajectory. Although it is proved to be effective, the methods are so complex to compute virtual electric functions that it is difficult to achieve realtime controls. In comparison, geometric methods have attracted considerable attention because of their simplified and real-time characteristics. Using parametric geometry curves, the methods generate trajectories by circular arcs, clothoids or splines, involving sines (Ni and Park, 2017), trapezoids (Ma et al., 2015) and B spline (Francis et al., 2016). You et al. (2015) introduced control of tracking trajectories by polynomial model of lane-change maneuvers. Bézier curves are adopted to generate a local lane-change path that enables the anti-collision behavior of a vehicle (Simba et al., 2016; Choe et al., 2016). The geometric algorithms could easily calculate the parameters of curves according to side constraints (e.g. start and end values of the trajectory, velocity and acceleration), but not process constraints. Thus, it is possible to propose a clear link between driving and vehicle characteristics and not only trajectory parameterization.

Furthermore, a controller that tracks the predefined trajectories accurately and guarantees stability according to the vehicles and traffic states should be developed to ensure improved lane-changing performance. Many related studies have been conducted in the authors' country and abroad (Zhang et al., 2017; Sun et al., 2018). Preview methods were previously used to minimize lateral trajectory tracking errors for traditional vehicles, including single-point and multi-point previews (Macadam, 1980). For self-driving vehicles, Emirler et al. (2014) designed a double integral action controller by PID to eliminate the lateral offset on the curvature (Peng et al., 2017). Its simple structure was easily implemented and demonstrated its acceptable tracking performance. However, the controller adjusted by experience was not satisfactory for applications that require high tracking accuracy. To adapt a vehicle to state-time variants and multi-constraint sets during lane changes, Benjamin et al. (2016) and Fitri et al. (2016) proposed a linear model by predictive control (MPC) algorithm for steering and tracking control. Nevertheless, most referred control algorithms based on linear systems were inadequate to describe actual vehicles. Therefore, considering the complexity of vehicle-driving scenarios and states, Cao et al. (2019) presented MPC with a nonlinear model for lane change, offering a better dynamics prediction and trajectory tracking. Based on a nonlinear MPC model of self-driving automotive vehicle, Attia et al. (2012, 2014) proposed a cruise-speed generation method. They designed a coupled controller with longitudinal and lateral strategy to optimize the adaptive cruise control. Cai et al. (2019) proposed a layered controller with a high-level MPC and a low-level energy-efficient to enhance lanechange feasibility and reduce energy expenditure (Xiong et al., 2018). Zhang et al. (2020) focused on the interference on rainy slippery road and proposed a robust controller as well as designed a dynamic simulation analysis system for articulated vehicles. The reference controllers were capable of dealing with parameter uncertainties with its prediction and optimization ability. However, the realtime and adjustability were limited. More importantly, the 
optimality with the finite-time-domain does not represent the stability of closed-loop systems.

In view of the abovementioned studies, there are many fruitful achievements in the safe lane-change for a single vehicle (Peng et al., 2019). However, some work still needs to be made a profound study to develop the intelligent methodology for self-driving articulated trucks further. First, the articulated truck is a complex coupled system, the lane-change path planning for the host vehicle and surrounding vehicles should consider not only the tractor's but also the coupled trailer's characteristics. Second, because of uncertainty parameters of articulated trucks, an excellent control strategy for eliminating the influence and maintaining the robust stability of the closed-loop coupled system warrants further study. Moreover, there is a lack of specialized hardware in the loop (HIL) platform to verify the control effects of self-driving articulated trucks, which should develop. Thus, this paper proposes a safe path planning and control method in lane change for self-driving articulated trucks in scenarios of the longitudinal forced lane change, such as anti-collision with obstacles ahead on a highway. The proposed safe lane-change path planning with a novel trajectory model combines the characteristics of self-driving articulated trucks and roads. And based on feedback linearization, a combined controller with feasible decision modes is designed to ensure tracking and stability. Furthermore, a specialized HIL platform is built, to simulate and verify the proposed methods. The proposed methods could effectively solve the problem of intelligent lane-change path planning and tracking control for articulated trucks.

Based on previous studies, applying double-Gaussian distribution and feedback linearization control (FLC) algorithm, we developed a lane-change path-planning model and regionalized anti-collision control strategy for self-driving articulated trucks under low traffic on highways. This study could provide a valuable reference for developing articulated vehicle driving safety assistants and intelligent vehicle control systems for decreasing major traffic accidents and improving the efficiency of commercial vehicles on highways. The structure of the paper is as follows. Section 2 provides an introduction of the safe lane-change path-planning model for articulated trucks. Section 3 deals with a control investigation for lane change. Section 4 shows the simulation tests by software

Figure 1 Illustration of articulated truck plane motion and trajectory reference

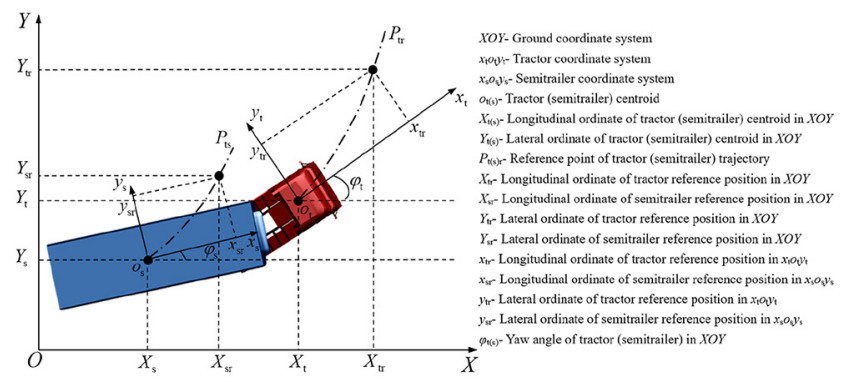

and the HIL platform for control verification in typical scenarios. Conclusions are provided in Section 5 to indicate future studies for research.

\section{Safe lane-change path planning}

\subsection{Lane-change trajectory model}

Defining ground coordinate system XOY, Figure 1 illustrates plane motion diagrams of an articulated truck involving a tractor and a semitrailer in coordinate systems $x_{\mathrm{t}} o_{\mathrm{t}} y_{\mathrm{t}}$ and $x_{\mathrm{s}} o_{\mathrm{s}} z_{\mathrm{s}}$. Using a double-car-like model for lateral dynamic, this work concerns the path planning and tracking control problems with a nonholonomic constraint that restricts vehicle planar motion without roll. The dynamics of the tractor and the semitrailer are denoted by the vector $\boldsymbol{V}=\left[X_{\mathrm{t}}, Y_{\mathrm{t}}, \varphi_{\mathrm{t}}, X_{\mathrm{s}}, Y_{\mathrm{s}}, \varphi_{\mathrm{s}}\right]$ in $X O Y$, where $\left(X_{\mathrm{t}}\right.$, $\left.Y_{\mathrm{t}}\right)$ and $\left(X_{\mathrm{s}}, Y_{\mathrm{s}}\right)$ are the locations of the centroids of the vehicles and $\varphi_{\mathrm{t}}$ and $\varphi_{\mathrm{s}}$ are the angles between the $x$-axis and $x_{\mathrm{t}}$-axis and $x_{\mathrm{s}}$-axis, respectively.

Figure 1 illustrates the difference from single vehicle, such as a passenger car. There are two interrelated trajectories coupled by the articulation angle. Therefore, the errors between the actual and reference parameters could be depicted by the coupled vehicles' positions and orientations, as follows:

$$
\left[\begin{array}{c}
x_{\mathrm{te}} \\
y_{\mathrm{te}} \\
\phi_{\mathrm{te}} \\
\theta_{\mathrm{e}}
\end{array}\right]=\left[\begin{array}{cccc}
\cos \varphi_{\mathrm{t}} & \sin \varphi_{\mathrm{t}} & 0 & 0 \\
-\sin \varphi_{\mathrm{t}} & \cos \varphi_{\mathrm{t}} & 0 & 0 \\
0 & 0 & 1 & 0 \\
0 & 0 & 0 & 1
\end{array}\right]\left[\begin{array}{c}
X_{\mathrm{t}}-X_{\mathrm{tr}} \\
Y_{\mathrm{t}}-Y_{\mathrm{tr}} \\
\varphi_{\mathrm{t}}-\varphi_{\mathrm{tr}} \\
\theta-\theta_{\mathrm{r}}
\end{array}\right]
$$

where $\left(x_{\text {te }}, y_{\text {te }}, \varphi_{\text {te }}, \theta_{\mathrm{e}}\right)$ are the errors of the tractor longitudinal displacement, lateral displacement, yaw angle and articulated angle in vehicles' coordinate systems. ( $X_{\mathrm{tr}}$, $\left.Y_{\mathrm{tr}}, \varphi_{\mathrm{tr}}, \theta_{\mathrm{r}}\right)$ indicates the reference parameters in $X O Y$. Obviously, the object of self-driving control is the less $\left(x_{\mathrm{te}}\right.$, $\left.y_{\text {te }}, \varphi_{\text {te }}, \theta_{\mathrm{e}}\right)$, the better tracking. The vehicle motion parameters referred to in this paper are defined as ground coordinate systems $X O Y$, except for particular explanation.

Based on actual tests of an articulated vehicle, the timedomain curves of the lateral velocities during the lanechange maneuver are shown in Figure 2. Figure 2 clearly shows the time phase and value differences between the two curves and approximate symmetry at some point on the time axis. Thus, double-Gaussian distribution functions

Figure 2 Vehicle lateral velocity test curves

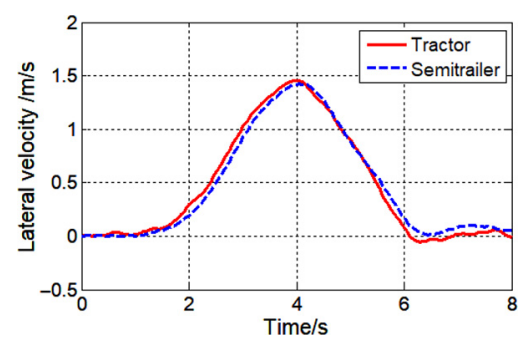


are introduced to fit the lateral velocities of the articulated vehicle as follows:

$$
\left\{\begin{array}{l}
V_{Y \mathrm{t}}\left(t_{i}\right)=\frac{d}{\sqrt{2 \pi} \sigma_{y \mathrm{t}}} \exp \left(\frac{-\left(t_{i}-\mu_{y}\right)^{2}}{2 \sigma_{y \mathrm{t}}^{2}}\right) \\
V_{Y \mathrm{~s}}\left(t_{i}\right)=\frac{d}{\sqrt{2 \pi} \sigma_{y \mathrm{~s}}} \exp \left(\frac{-\left(t_{i}-\mu_{y}-\Delta t_{i}\right)^{2}}{2 \sigma_{y \mathrm{~s}}^{2}}\right)
\end{array}\right.
$$

where $V_{Y_{\mathrm{t}}}$ and $V_{Y_{\mathrm{s}}}$ are, respectively, the lateral velocities of the tractor and the semitrailer, $t_{i}$ is the vehicle-driven time and $i=1$, $2,3, \ldots n, \Delta t_{i}$ is the time-phase difference between the tractor and the semitrailer and $d, \mu_{y}, \sigma_{y \mathrm{t}}$ and $\sigma_{y \mathrm{~s}}$ are the fitting coefficients.

Generally, the tractor and semitrailer could not complete lane change during a whole sinusoidal cycle. Thus, here we introduce probability coefficients to describe the complete degree of lane change associated with $\sigma_{y \mathrm{t}}$ and $\sigma_{y \mathrm{~s}}$. Related parameters in equation (2) could be obtained by:

$$
\left\{\begin{array}{l}
d=B \\
\mu_{y}=t_{0}+1 /(2 f)+t_{\mathrm{d}} \\
P_{\mathrm{t}}=P\left\{\mu_{y}-\lambda \sigma_{y \mathrm{t}}<t<\mu_{y}+\lambda \sigma_{y \mathrm{t}}\right\}=\Phi\left(\lambda_{\mathrm{t}}\right) \\
\sigma_{y \mathrm{t}}=\left(1 / f+2 t_{\mathrm{d}}\right) / \lambda_{\mathrm{t}} \\
P_{\mathrm{s}}=P\left\{\mu_{y}+\Delta t-\lambda_{\mathrm{s}} \sigma_{y \mathrm{~s}}<t<\mu_{y}+\Delta t+\lambda_{\mathrm{s}} \sigma_{y \mathrm{~s}}\right\}=\Phi\left(\lambda_{\mathrm{s}}\right) \\
\sigma_{y \mathrm{~s}}=\left(1 / f+2 t_{\mathrm{d}}+2 \Delta t\right) / \lambda_{\mathrm{s}}
\end{array}\right.
$$

where $B$ is the width of each lane, $f$ is the steering frequency, $t_{0}$ is the decision time of the intelligent system, $t_{\mathrm{d}}$ is the lateral velocity response delay time closely related to vehicle characteristics and $\Delta t$ is the average delay time. $P_{\mathrm{t}}, P_{\mathrm{s}}, \lambda_{\mathrm{t}}$ and $\lambda_{\mathrm{s}}$ are the probability coefficients; and $\lambda_{\mathrm{t}}$ and $\lambda_{\mathrm{s}}$ are set to 4-6 according to actual vehicle dynamics and scenarios.

$\lambda_{\mathrm{t}}$ and $\lambda_{\mathrm{s}}$ are key coefficients to determine the maximum values of vehicles' lateral velocities and accelerations. Figure 3 shows the tractor lateral velocity-changing trend with different $\lambda_{\mathrm{t}}$. In general, larger $\lambda_{\mathrm{t}}$ means the higher peak of the value. Thus, vehicle states in lane change could be defined by selecting $\lambda_{\mathrm{t}}$ appropriately, still, the correlation between $\lambda_{\mathrm{t}}$ and $\lambda_{\mathrm{s}}$ should be reasonably determined according to the actual articulated vehicle dynamics.

By equations (2) and (3), trajectories of the tractorsemitrailer during lane change could be quantifiably described, involving reaction and response times, manipulated inputs and

Figure 3 Tractor lateral velocity variation with $\lambda_{\mathrm{t}}$

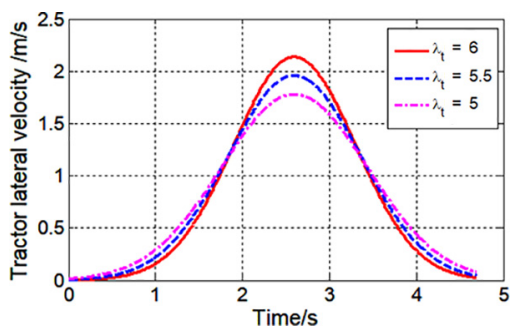

dynamic outputs. The parameters in the model can be matched reasonably according to the actual vehicle and road conditions.

\subsection{Safe lane-change constraint}

Safe lane-change constraint is the key to ensure the coupling vehicles' tracking and stability, which needs to satisfy kinematics and dynamics. The principles ensuring that an articulated truck achieves safe lane-change can be described as follows;

- A host vehicle involving a tractor and a semitrailer should perform anti-collision with an obstacle ahead.

- The host vehicle should steer return timely and the overall lateral displacement should satisfy the distance from object lanes.

- The host vehicle is guaranteed tracking and robust stability and comfort in the lane change.

For the kinematic constraints, Figure 4 describes a critical relative position between a vehicle ahead and an articulated truck while lane changing. The relative critical attitude of the vehicles is determined by both geometric sizes and dynamic parameters, such as vehicle width, centroid location, road width and yaw angles. It also shows that different from single vehicles. The articulated truck should ensure stability and safety. Therefore, the critical states for safe lane-change lie in not only the semitrailer's attitude but also the relationship between the tractor and the semitrailer.

Vehicle dynamics constraints can be expressed by the most basic indexes, lateral accelerations of the tractor and semitrailer. In addition to the proposed principles and the critical geometry relationship shown in Figure 4, the constraint conditions of safe lane-change for a self-driving articulated truck are defined by the geometric sizes and dynamic parameters as follows:

$$
\left\{\begin{array}{l}
Y_{\mathrm{s}}\left(t_{i}\right) \geq \frac{B_{0}}{2}+\left[\left(b_{\mathrm{s}}+b_{\mathrm{s}}^{\prime}\right) \sin \varphi_{\mathrm{s}}\left(t_{i}\right)+\frac{B_{\mathrm{s}}}{2} \cos \varphi_{\mathrm{s}}\left(t_{i}\right)\right] \\
Y_{\mathrm{tmax}} \leq B, Y_{\mathrm{s} \max } \leq B \\
\left|a_{Y \mathrm{t}}\left(t_{i}\right)_{\max }\right| \leq a_{Y \max },\left|a_{Y \mathrm{~s}}\left(t_{i}\right)_{\max }\right| \leq a_{Y \max }
\end{array}\right.
$$

and

$$
\varphi_{\mathrm{s}}\left(t_{i}\right)=V_{Y \mathrm{~s}}\left(t_{i}+\Delta t_{n}\right) / V_{X \mathrm{~s}}\left(t_{i}+\Delta t_{n}\right)
$$

where $Y_{\mathrm{s}}$ is the lateral displacement of the semitrailer. $B_{0}$ is the width of the obstacle ahead; $B_{\mathrm{t}}$ and $B_{\mathrm{s}}$ are, respectively, the widths of the tractor and the semitrailer; $b_{\mathrm{s}}$ is the distance from the semitrailer's centroid $o_{\mathrm{s}}$ to the rear axle; and $b$ ' ${ }_{\mathrm{s}}$ is the rearoverhang length of the semitrailer. $\varphi_{\mathrm{s}}$ is the yaw angle of the semitrailer. $a_{Y \max }$ is the permitted maximum of the lateral acceleration determined by the road and the tire characteristics.

Figure 4 Critical position of safe lane-change

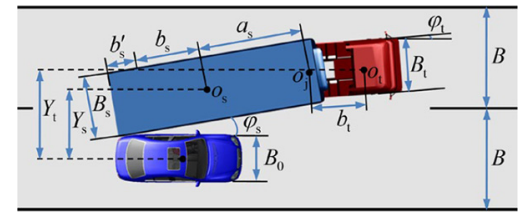


$\Delta t_{n}$ is the time-phase difference between the lateral velocity and the yaw angle.

\subsection{Minimum safe distance model}

The minimum safe distance is defined as the minimum clearance where the articulated truck can safely change lane and perform anti-collision with vehicles or obstacles ahead. The scenarios involved in this study are longitudinal forced lane changes; the influences of side interferences are not mentioned here.

In equation (4), the vehicle structure sizes, $b_{\mathrm{s}}>B_{\mathrm{s}} / 2$ and the vehicles' yaw angles $\varphi_{\mathrm{t}}$ and $\varphi_{\mathrm{s}}$ are relatively small and generally less than $10^{\circ}$ (Peng et al., 2012). In this case, the safe lateral displacement for collision avoidance is positively correlated with the yaw angle of the semitrailer. Therefore, the conservative value of the safe lateral displacement is obtained based on the maximum values of the yaw angle and the angle could be approximately calculated by the ratio of lateral velocity to longitudinal velocity as follows:

$$
\left\{\begin{array}{l}
Y_{\mathrm{s}}\left(t_{\mathrm{p}}\right)=\frac{B_{0}}{2}+\left[\left(b_{\mathrm{s}}+b_{\mathrm{s}}^{\prime}\right) \sin \varphi_{\mathrm{s}}(t)_{\max }+\frac{B_{\mathrm{s}}}{2} \cos \varphi_{\mathrm{s}}(t)_{\max }\right] \\
\phi_{\mathrm{s}}(t)_{\max }=\left[V_{Y_{\mathrm{s}}}\left(t_{i}\right) / V_{X \mathrm{~s}}\left(t_{i}\right)\right]_{\max }
\end{array}\right.
$$

where $t_{\mathrm{p}}$ is the critical time for anti-collision and $t_{\mathrm{j}}$ is the corresponding time when the lateral velocity reaches the maximum value.

Figure 5 Contrasts in constant longitudinal velocity maneuver

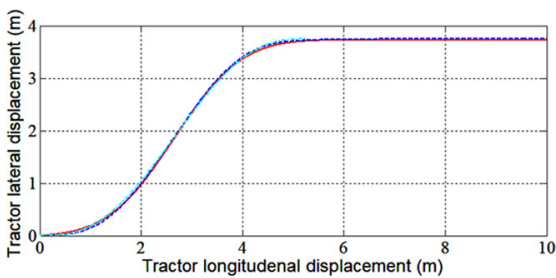

(a)

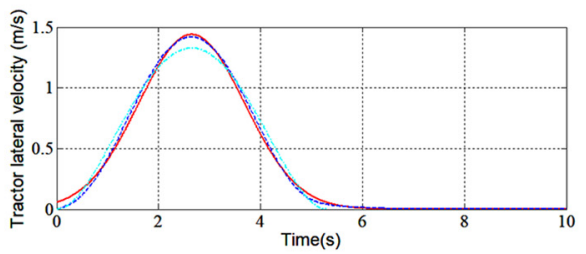

(c)

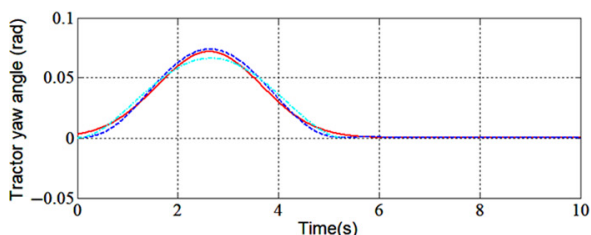

(e)
If the $Y_{\mathrm{s}}\left(t_{\mathrm{p}}\right)$ is calculated by equation (4), the $t_{\mathrm{p}}$ could be obtained according to the $Y_{\mathrm{s}}-t$ curve of the semitrailer, then, the minimum safe distance in the longitudinal direction can be calculated, according to the longitudinal movement of the vehicle. Two cases are considered here: constant velocity and uniform deceleration, which are, respectively, described as:

$$
L_{\mathrm{m}}=\int_{0}^{t_{\mathrm{p}}} \Delta V_{X} d t+l_{\mathrm{s}}
$$

where $L_{\mathrm{m}}$ is the minimum of the safe distance, $l_{\mathrm{s}}$ is the conservative safety clearance and set as $10 \mathrm{~m}$ here and $\Delta V_{X}$ is the relative longitudinal velocity between the host vehicle and the obstacle ahead.

\subsection{Model validation}

The model validation is carried out on a physical simulation platform, Trucksim, which provides advanced and professional development tools for tractor-semitrailer dynamics. Here, lateral velocities and yaw angles of the tractor and the semitrailer are concerned and contrasted by the double-Gaussian model, Trucksim and polynomial model. With $20 \mathrm{~m} / \mathrm{s}$ initial longitudinal velocity and $0.2 \mathrm{~Hz}$ steering frequency, the contrasts are conducted in constant and $2 \mathrm{~m} / \mathrm{s}^{2}$ deceleration without operation delays, respectively. Details are shown in Figures 5 and 6.

Figures 5 and 6 clearly show the trends of typical parameters, including vehicle trajectories, lateral velocities

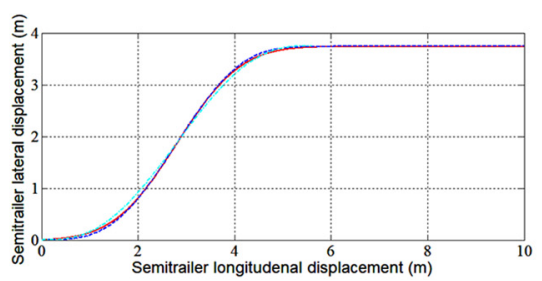

(b)

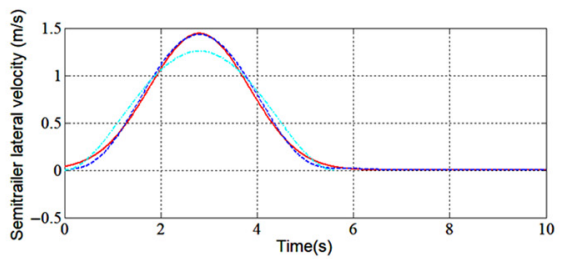

(d)

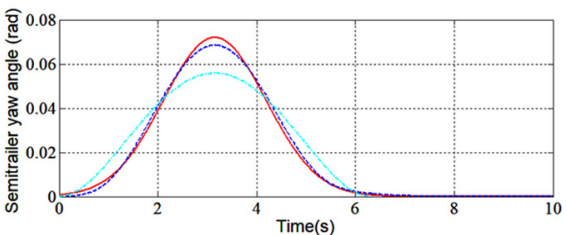

(f) Double-Gaussian model $\quad$----- Trucksim $\cdots \cdots$ Polynomial model

Notes: (a) Tractor trajectory; (b) semitrailer trajectory; (c) tractor lateral velocity; (d) semitrailer lateral velocity; (e) tractor yaw angle; and (f) semitrailer yaw angle. 
Figure 6 Contrasts in longitudinal deceleration maneuver

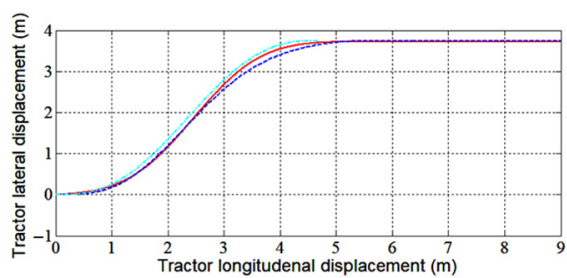

(a)

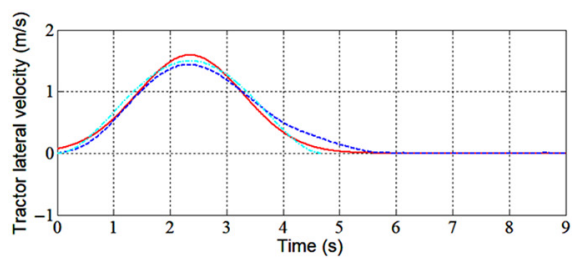

(c)

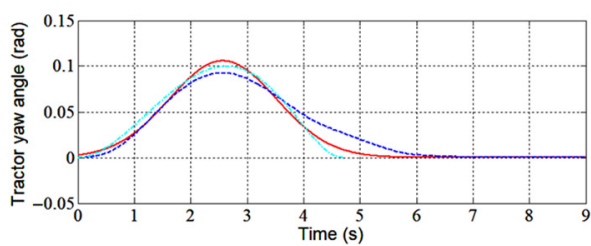

(e)

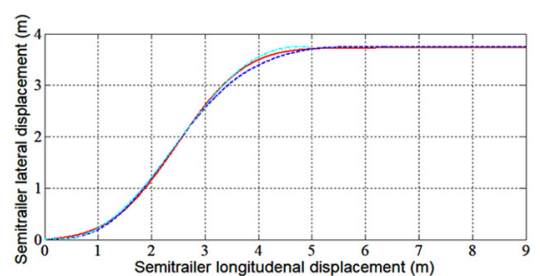

(b)

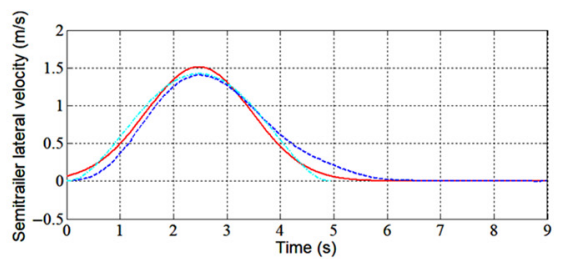

(d)

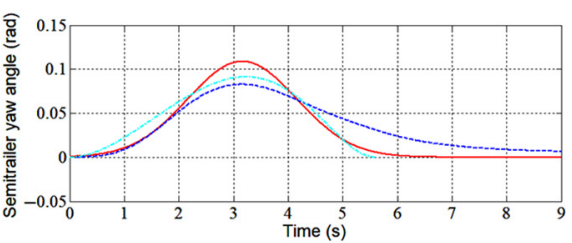

(f)

-Double-Gaussian model $\quad$----- Trucksim $\quad \cdots \quad$ Polynomial model

Notes: (a) Tractor lateral velocity; (b) semitrailer lateral velocity; (c) tractor lateral velocity; (d) semitrailer lateral velocity; (e) tractor yaw angle; and (f) semitrailer yaw angle

and yaw angles obtained by the double-Gaussian model, Trucksim and polynomial model. In the constant longitudinal velocity maneuver, the trajectories have better consistency with Trucksim, and in addition to the lateral velocities and yaw angles of tractor and semitrailer, the overall error is less than 5\%, much better than the polynomial model whose error is more than $10 \%$. Moreover, in the longitudinal deceleration maneuver, the errors of relative parameters are relatively larger than the polynomial model, especially the yaw angle of the semitrailer, the maximum error is close to $20 \%$; however, it has little effect on the minimum of the safe distance $L_{\mathrm{m}}$ and the fitting degree of each stage and the whole is better than the polynomial model. More comparisons are conducted between Gaussian model and Trucksim, to verify the reliability, as listed in Table 1.

As shown in Table 1, some key parameters obtained via the path-planning model, have better consistency with the Trucksim. Most of the errors are less than $10 \%$ and the minimum of the safe distances $L_{\mathrm{m}}$ are less than $7 \%$. Furthermore, the $L_{\mathrm{m}}$ obtained by the proposed model is generally larger than that obtained by Trucksim, which indicates the estimations are relatively conservative and safe. Thus, from the perspective of track and lateral motion, the proposed path-planning model can approximately reflect the actual lane-changing state of vehicles.

\section{Safe lane-change controller}

\subsection{Safe lane-change decision mode}

Decision mode is an important part for safe lane-change path planning. As an intermediate link between perception and control, the proposed safe lane-change decision mode for anti-collision should ensure not only longitudinal safety space but also lateral stability, passenger comfort and driving simplicity.

The authors take a set of vehicle and road data as an example, as shown in Table 2. With an initial velocity of $20 \mathrm{~m} / \mathrm{s}$ and appropriate steering frequencies, the minimum vehicle safe distances with two types of maneuvers (constant velocity and $2 \mathrm{~m} / \mathrm{s}^{2}$ deceleration) could be calculated by the proposed pathplanning model, as listed in Table 2 .

As shown in Table 2, with the steering frequency increasing from $0.2 \mathrm{~Hz}$ to $0.5 \mathrm{~Hz}$, the minimum safe distance diminishes by nearly $36 \%$ from $84.40 \mathrm{~m}$ to $53.85 \mathrm{~m}$ in a constant speed and by nearly $28 \%$ from $72.37 \mathrm{~m}$ to $52.15 \mathrm{~m}$ in braking maneuver. Moreover, the vehicle lateral acceleration increases from $0.84 \mathrm{~m} / \mathrm{s}^{2}$ to $4.69 \mathrm{~m} / \mathrm{s}^{2}$ and $1.03 \mathrm{~m} / \mathrm{s}^{2}$ to $4.48 \mathrm{~m} / \mathrm{s}^{2}$, nearly 5.6 and 4.5 times, respectively.

Moreover, under the same condition (with or without braking), higher steering frequency causes smaller safe distance and critical time point, but greater lateral deceleration. Furthermore, compared with constant speed maneuver, braking could make 


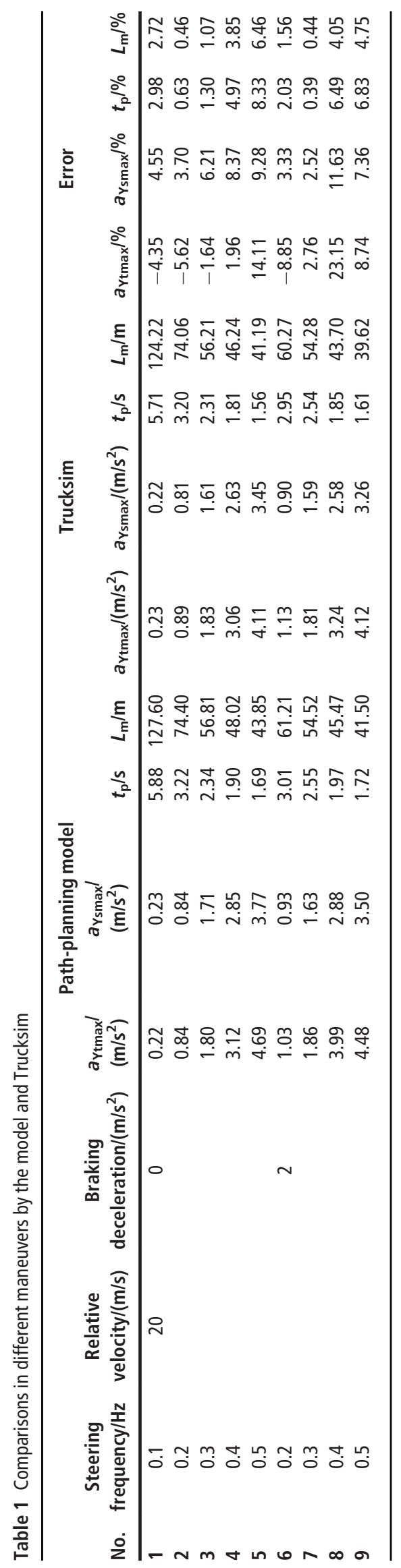


Table 2 Vehicle safe distances in different modes

\begin{tabular}{|c|c|c|c|c|c|c|c|c|}
\hline No. & Steering frequency /Hz & $\begin{array}{l}\text { Relative velocity } \\
\qquad /(\mathrm{m} / \mathrm{s})\end{array}$ & $\begin{array}{l}\text { Decision time } \\
\text { /s }\end{array}$ & $\begin{array}{l}\text { Braking deceleration } \\
\qquad /\left(\mathrm{m} / \mathrm{s}^{2}\right)\end{array}$ & Braking response time/s & $a_{Y \max } /\left(\mathrm{m} / \mathrm{s}^{2}\right)$ & $t_{\mathrm{p}} / \mathrm{s}$ & $L_{\mathrm{m}} / \mathrm{m}$ \\
\hline 1 & 0.1 & 20 & 0.5 & 0 & 0 & 0.22 & 6.38 & 137.61 \\
\hline 2 & 0.2 & & & & & 0.84 & 3.72 & 84.40 \\
\hline 3 & 0.3 & & & & & 1.80 & 2.84 & 66.81 \\
\hline 4 & 0.4 & & & & & 3.12 & 2.40 & 58.02 \\
\hline 5 & 0.5 & & & & & 4.69 & 2.19 & 53.85 \\
\hline 6 & 0.2 & & & 2 & 0.2 & 1.03 & 3.61 & 72.37 \\
\hline 7 & 0.3 & & & & & 1.86 & 3.05 & 65.50 \\
\hline 8 & 0.4 & & & & & 3.99 & 2.47 & 56.22 \\
\hline 9 & 0.5 & & & & & 4.48 & 2.22 & 52.15 \\
\hline
\end{tabular}

Table 3 Four-level lane changing modes for anti-collision

\begin{tabular}{|c|c|c|c|c|c|c|}
\hline Mode & $\begin{array}{c}\text { Steering } \\
\text { frequency } \\
\text { /Hz }\end{array}$ & $\begin{array}{l}\text { Host vehicle initial } \\
\text { velocity } \\
/ \mathrm{m} / \mathrm{s}\end{array}$ & $\begin{array}{l}\text { Decision } \\
\text { time } \\
\text { /s }\end{array}$ & $\begin{array}{c}\text { Uniform } \\
\text { deceleration } \\
/ \mathrm{m} / \mathrm{s}^{2}\end{array}$ & $\begin{array}{c}\text { Braking response } \\
\text { time } \\
\text { /s }\end{array}$ & Applicable condition \\
\hline 1 & 0.1 & 20 & 0.5 & 0 & 0 & $6.38 \Delta L+\left(V^{\prime} x_{0} t_{\mathrm{p}}+\frac{1}{2} a_{0} t_{\mathrm{p}}^{2}\right)+I_{\text {safe }} \geq 138$ \\
\hline 2 & 0.2 & & & 0 & 0 & $3.7285 \leq \Delta L+\left(V^{\prime} x_{0} t_{\mathrm{p}}+\frac{1}{2} a_{0} t_{\mathrm{p}}^{2}\right)+I_{\text {safe }}<138$ \\
\hline 3 & 0.3 & & & 0 & 0 & $2.8467 \leq \Delta L+\left(V^{\prime}{ }_{x_{0}} t_{\mathrm{p}}+\frac{1}{2} a_{0} t_{\mathrm{p}}^{2}\right)+I_{\text {safe }}<85$ \\
\hline 4 & 0.4 & & & 2 & 0.2 & $2.4757 \leq \Delta L+\left(V^{\prime} x_{0} t_{p}+\frac{1}{2} a_{0} t_{p}^{2}\right)+I_{\text {safe }}<67$ \\
\hline
\end{tabular}

shorter safe distance but possibly more lateral acceleration, such as in $0.2 \mathrm{~Hz}$, the length decreases by nearly $14 \%$ and the lateral acceleration increases by almost $23 \%$. Therefore, it can be included that the steering frequency is a crucial factor in not only enhancing longitudinal safety but also deteriorating lateral stability. Meanwhile, braking is also an effective way to enlarge anti-collision safety space but may increase lateral acceleration, as well. The coupled longitudinal and lateral motions may require higher road adhesion to ensure safety.

Based on the calculated minimum safe distances in different maneuvers from one to nine in Table 2 and considering simplicity driving and comfort riding, the authors propose four-level selfdriving modes of lane change for anti-collision under specific conditions, as listed in Table 3. It indicates the applicable conditions of four-level self-driving modes, which are used as the intelligent decision mechanism. Data in Table 3 show the acceptable initial relative distances between the vehicles $\Delta L$ and self-driving modes, which could be defined according to the actual dynamics of the vehicles. The authors define the obstacle $V_{X 0}$ is in the region $[0,20] \mathrm{m} / \mathrm{s}$ with the interval of $10 \mathrm{~m} / \mathrm{s}$ and the deceleration of the obstacle $a_{0}$ is in $[-8,0] \mathrm{m} / \mathrm{s}^{2}$ and $-2 \mathrm{~m} / \mathrm{s}^{2}$ interval. The vehicle acceptable safe distances in four-level modes are calculated and shown in Figure 7.

\subsection{Vehicle model for controller}

As shown in Figure 1, while steering, there is a longitudinal and lateral coupling movement of the vehicle, as well as a yaw motion caused by the rotational moment because of lateral forces around the mass center. Therefore, an eight-degree-offreedom (DOF) vehicle model, including vehicle longitudinal, lateral and yaw motions and front/rear wheels' rolling motions is established as follows:

$$
\left\{\begin{array}{c}
\dot{\boldsymbol{X}}=f(\boldsymbol{X})+g(\boldsymbol{X}) \boldsymbol{u} \\
\boldsymbol{X}=\left[x_{1}, x_{2}, x_{3}, x_{4}, x_{5}, x_{6}, x_{7}, x_{8}, x_{9}, x_{10}, x_{11}\right]^{\mathrm{T}} \\
=\left[V_{X \mathrm{t}}, V_{Y_{\mathrm{t}}}, \dot{\varphi}_{\mathrm{t}}, \varphi_{\mathrm{t}}, \dot{\theta}, \theta, \omega_{\mathrm{tf}}, \omega_{\mathrm{tr}}, \omega_{\mathrm{s}}, \dot{\delta}_{\mathrm{f}}, \delta_{\mathrm{f}}\right]^{\mathrm{T}}
\end{array}\right.
$$

Setting the control output variables, including the tractor's longitudinal $V_{X \mathrm{t}}$, lateral velocities $V_{Y \mathrm{t}}$, yaw angle $\varphi_{\mathrm{t}}$, front wheel steering angle $\delta_{\mathrm{f}}$ and articulated angle $\theta$ and applying the typical control strategies of active front steering (AFS) and direct yaw control (DYC), the vehicle control model is expressed as:

$$
\begin{aligned}
& \left\{\begin{array}{l}
\dot{\boldsymbol{X}}=f(\boldsymbol{X})+g(\boldsymbol{X}) \mathbf{u} \\
h(\boldsymbol{X})=\left[\begin{array}{lllll}
V_{X \mathrm{t}} & V_{Y \mathrm{t}} & \varphi_{\mathrm{t}} & \theta & \delta_{\mathrm{f}}
\end{array}\right]^{\mathrm{T}}
\end{array}\right. \\
& g(\boldsymbol{X})=\left[\boldsymbol{g}_{1}, \boldsymbol{g}_{2}, \boldsymbol{g}_{3}, \boldsymbol{g}_{4}, \boldsymbol{g}_{5}\right] \\
& \mathbf{u}=\left[\begin{array}{lllll}
u_{1} & u_{2} & u_{3} & u_{4} & u_{5}
\end{array}\right]^{\mathrm{T}} \\
& =\left[\begin{array}{lllll}
F_{x \mathrm{fc}} & F_{x \mathrm{rc}} & F_{x \mathrm{sc}} & M_{\mathrm{c}} & \delta_{\mathrm{swc}}
\end{array}\right]^{\mathrm{T}}
\end{aligned}
$$

Relevant descriptions are listed in Appendix 2. 
Figure 7 Vehicle safe distances in four-level lane changing modes

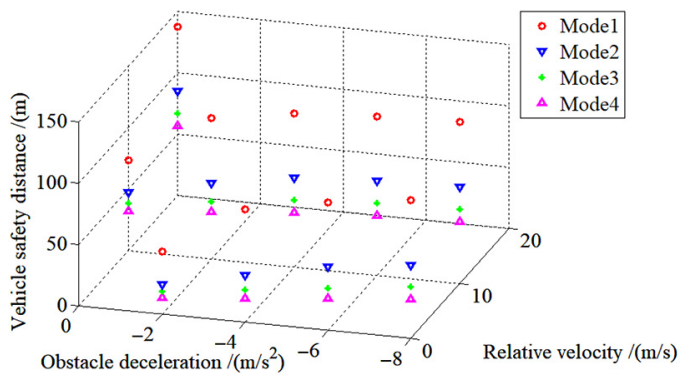

Figure 8 Structure of the safe lane-change control system

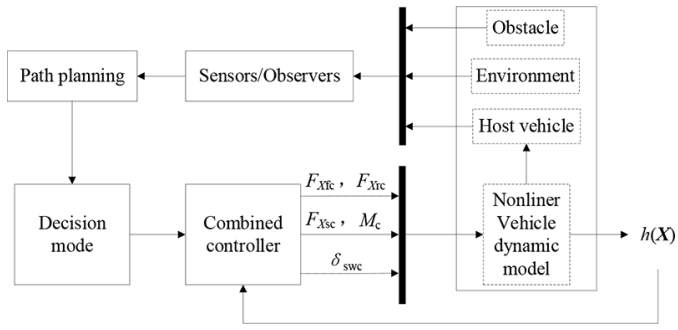

Figure 9 Model comparative study for the combined controller

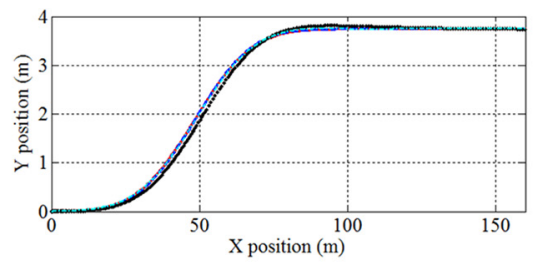

(a)

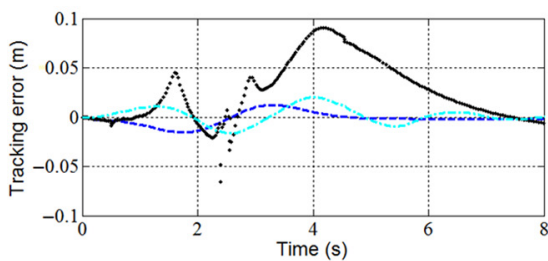

(c)

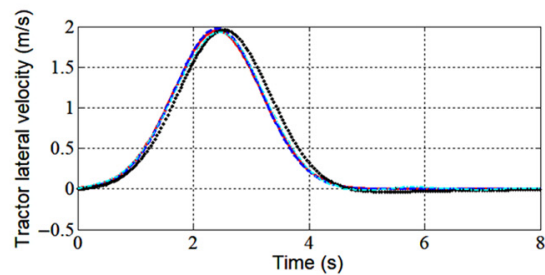

(e)

\subsection{Combined controller design}

Because of the influence of the vehicle parameter uncertainty, a controller is to guarantee the tracking and robust stability of the closed-loop coupled system. Thus, the controller is designed based on FLC theory combined with single point preview optimization (Hitay, 2019).

According to FLC theory, an input-output linearization is deduced and the control model is defined as:

$$
\mathbf{y}_{n}^{(i)}=\frac{\partial\left(L_{f}^{i-1} h\right)}{\partial x}[f(\boldsymbol{X})+g(\boldsymbol{X}) \boldsymbol{u}]=L_{f}^{i} h(\mathbf{X})+L_{g} L_{f}^{i-1} h(\boldsymbol{X}) \boldsymbol{u}
$$

if $h(\boldsymbol{X})$ satisfies:

$$
L_{g} L_{f}^{i-1} h(\boldsymbol{X})=0, i=1,2, \cdots, \rho-1 ; L_{g} L_{f}^{\rho-1} h(\boldsymbol{X}) \neq 0
$$

then,

$$
\mathbf{y}_{n}^{(\rho)}=L_{f}^{\rho} h(\boldsymbol{X})+L_{g} L_{f}^{\rho-1} h(\boldsymbol{X}) \boldsymbol{u}=\boldsymbol{v}
$$

According to the feedback linearization derivation principle, it indicates that the relative degree of the vehicle system is 8 less than 11, which satisfies partial feedback linearization.

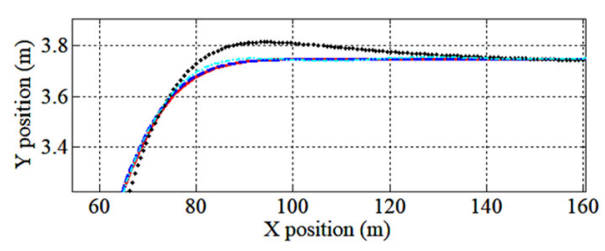

(b)

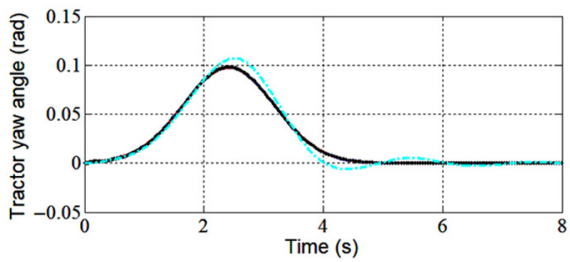

(d)

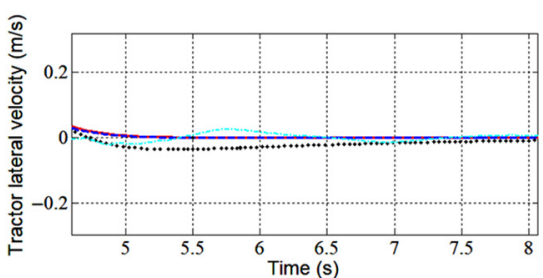

(f)

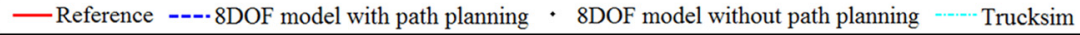

Notes: (a) Global path; (b) local enlarger of the global path; (c) tracking error; (d) tractor yaw angle; (e) Tractor lateral velocity; and (f) local enlarger of the tractor lateral velocity 
Figure 10 Control effects in different modes for anti-collision on a straight road

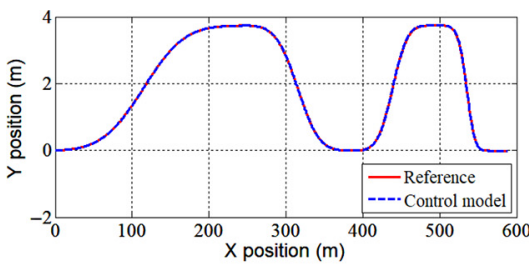

(a)

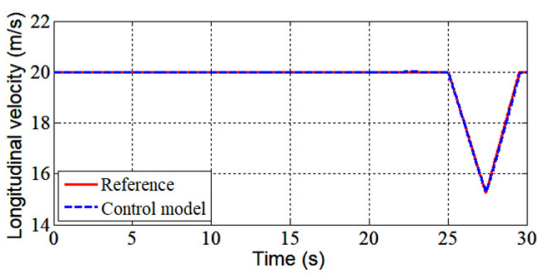

(c)

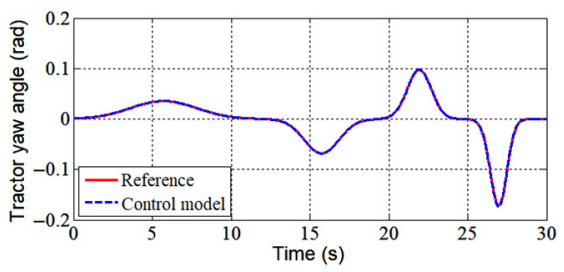

(e)

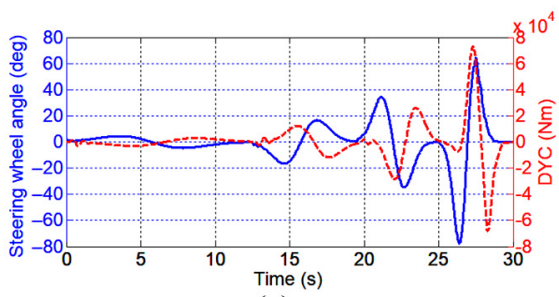

(g)

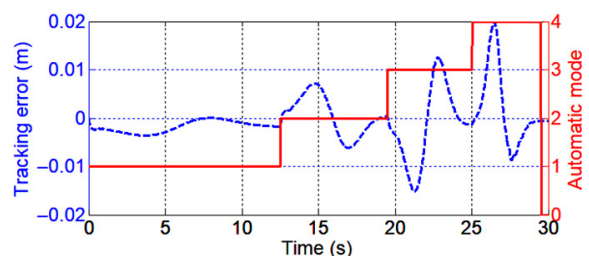

(b)

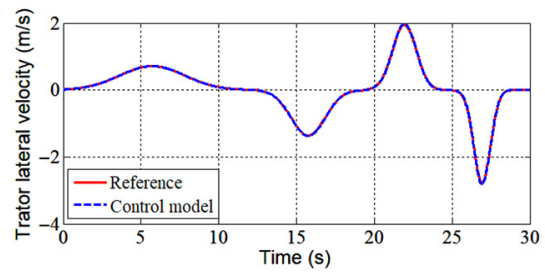

(d)

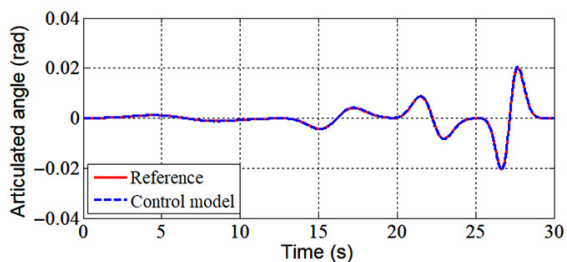

(f)

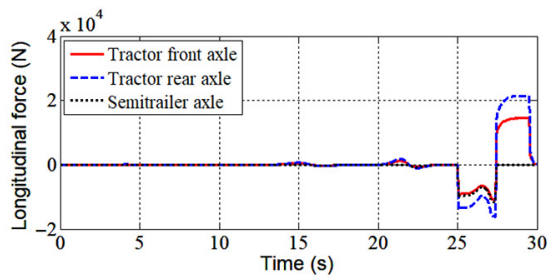

(h)

Notes: (a) Global path; (b) tracking error and automatic mode; (c) longitudinal velocity;

(d) tractor lateral velocity; (e) tractor yaw angle; (f) articulated angle; (g) control inputs of AFS and DYC; (h) control inputs of wheels' longitudinal forces

Coordinate transformation is necessary for the model, as detailed further:

$$
\boldsymbol{Z}=T \boldsymbol{X}
$$

where $T$ is a nonsingular $11 \times 11$ matrix. Then, the control model by partial feedback linearization could be expressed as:

$$
\left\{\begin{array}{l}
\dot{\boldsymbol{\xi}}=A_{\mathrm{c}} \xi+B_{\mathrm{c}} \gamma(\boldsymbol{X})[\mathbf{u}-\alpha(\boldsymbol{X})] \\
\dot{\boldsymbol{\eta}}=q_{0}(\boldsymbol{\eta}, \xi) \\
\mathbf{y}=C_{\mathrm{c}} \xi
\end{array}\right.
$$

where $\xi=\left[z_{1}, z_{2}, z_{3}, z_{4}, z_{5}, z_{6}, z_{7}, z_{8}\right]^{\mathrm{T}}$ and $\boldsymbol{\eta}=\left[z_{9}, z_{10}, z_{11}\right]$. The control inputs $\boldsymbol{v}$ can be expressed as:

$$
\mathbf{v}=\gamma(\boldsymbol{X})[\mathbf{u}-\alpha(\boldsymbol{X})]
$$

Then, the initial nonlinear system could be linearized as $\dot{\xi}=A_{\mathrm{c}} \xi+B_{\mathrm{c}} \mathbf{v}$.
Figure 8 shows a designed safe lane-change control system. Feasible path planning is carried out and safe trajectories satisfying constraint conditions are generated by detecting the information of the vehicles and environment by sensors' perception, involving velocity, distance and road adhesion. Then, an optimized trajectory is determined by the intelligent decision mode, which considers safety combined with comfort and traffic efficiency.

By exponent and proportional gain, convergence rules are established through the state variable errors as follows:

$$
\mathbf{v}=\lambda \mathbf{e}+\dot{\mathbf{y}}_{\mathrm{r}}
$$

where $\boldsymbol{e}$ is the tracking error between the vehicle's actual motions and the objects, which can be transformed as:

$$
\dot{\mathbf{e}}+\lambda \mathbf{e}=0
$$

Moreover, the steering angle input $v_{5}$ is controlled by single point preview, which is defined as: 
Figure 11 Control effects of specific modes for anti-collision on a curved road

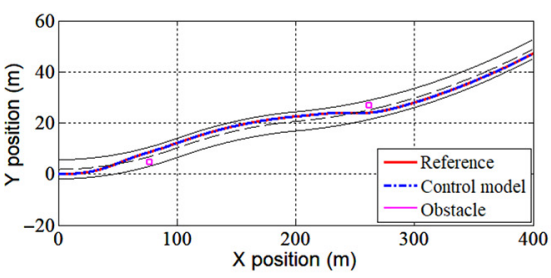

(a)

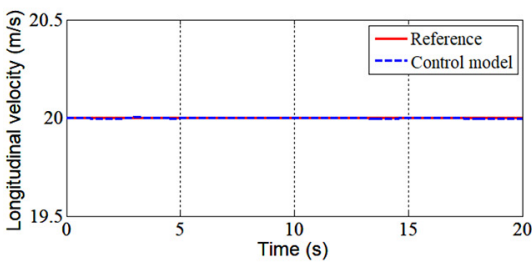

(c)

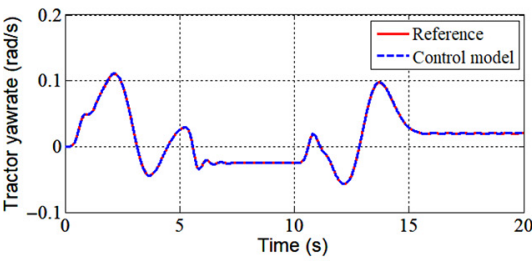

(e)

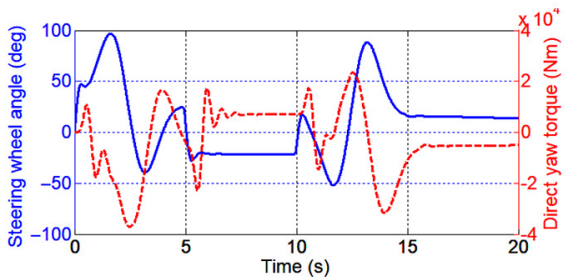

(g)

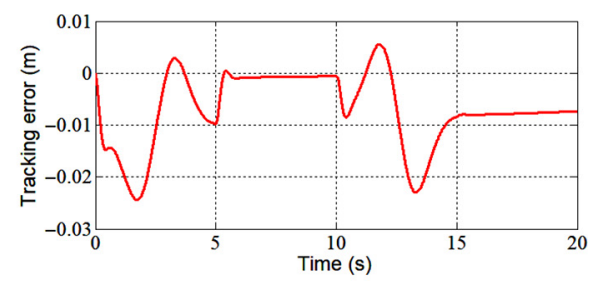

(b)

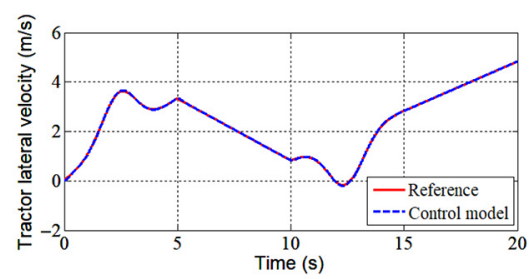

(d)

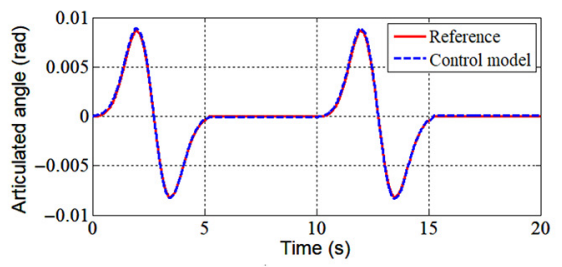

(f)

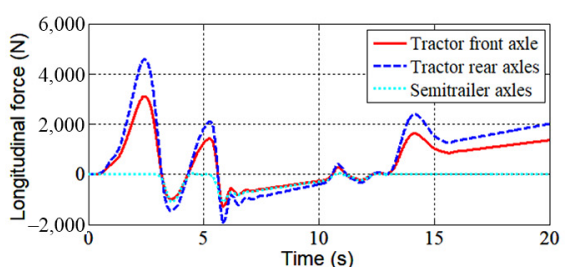

(h)

Notes: (a) Global path; (b) tracking error; (c) longitudinal velocity; (d) lateral velocity; (e) lateral acceleration; (f) yawrate; (g) control inputs of AFS and DYC; (h) control inputs of longitudinal forces

Figure 12 HIL simulation platform

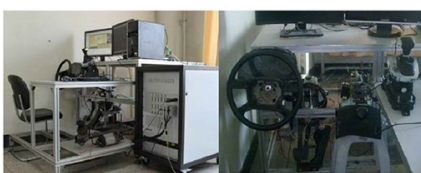

(a)

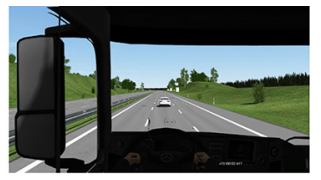

(b)
Notes: (a) Physical system of HIL simulation platform; (b) software system of HIL simulation platform

$$
v_{5}=K\left[Y_{\mathrm{r}}\left(t+T_{\mathrm{p}}\right)-Y(t)-T V_{Y}(t)\right]+L_{f}^{2} h_{5}(x)
$$

where $v_{5}$ is a set based on optimal algorithm. $T_{\mathrm{p}}$ is the preview time. The closed-loop gain $K$ could guarantee the path tracking and robust stability of the vehicle system.
Table 4 Defining values in HIL

\begin{tabular}{ccccccccccc}
\hline$B / m$ & $\mu$ & $a_{s} / m$ & $b_{s} / m$ & $b_{s}^{\prime} / m$ & $b_{t} / m$ & $B_{s} / m$ & $B_{0} / m$ & $I_{s} / m$ & $\lambda_{t}$ & $\lambda_{s}$ \\
\hline 3.75 & 0.8 & 5.05 & 2.9 & 2.03 & 2.07 & 2.6 & 2.4 & 10 & 4.7 & 4.7
\end{tabular}

The combined controller concern on the nonlinear characteristics of high-speed vehicles, and could improve the tracking accuracy and robustness even in case of interference.

\section{Control effects verification}

\subsection{Algorithm verification}

To verify the effects of the proposed control algorithm associated with the path planning and the decision mode, the authors compare it with the other controller (based on 
Figure 13 Tractor motions in lane change obtained by HIL simulation platform

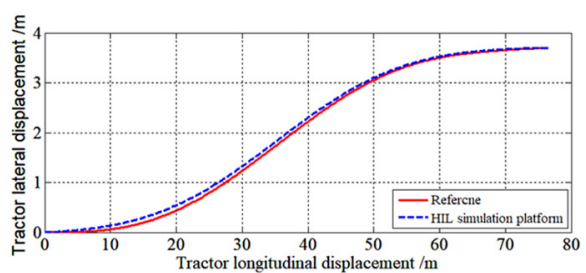

(a)

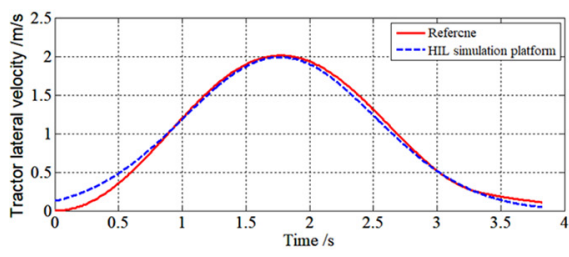

(c)

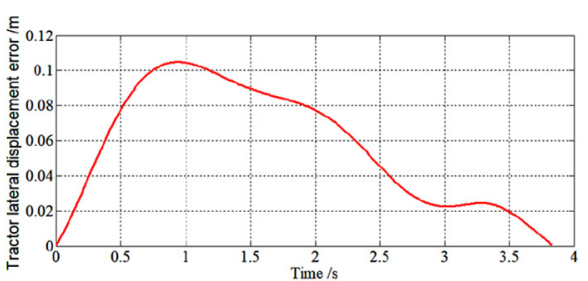

(b)

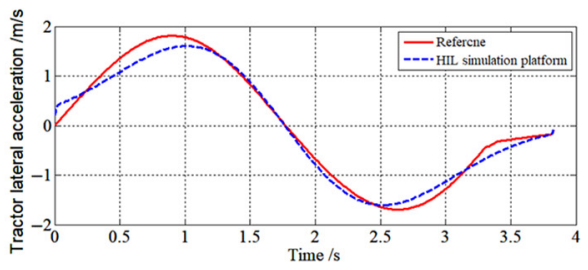

(d)

Notes: (a) Tractor trajectory; (b) lateral displacement error; (c) lateral velocity;

(d) lateral acceleration

Table 5 Effect verification of HIL

\begin{tabular}{|c|c|c|c|c|c|c|c|c|c|}
\hline Constant speed & $\begin{array}{l}\text { Initial speed } \\
\qquad / \mathrm{m} / \mathrm{s}\end{array}$ & Probability coefficient $\lambda$ & Steering frequency /Hz & $\begin{array}{c}V_{Y c}(t)_{\max } \\
/ \mathrm{m} / \mathrm{s}\end{array}$ & $\begin{array}{c}a_{Y c}(t)_{\max } \\
/ \mathrm{m} / \mathrm{s}^{2}\end{array}$ & $\begin{array}{l}a_{Y c}(t)_{\min } \\
/ \mathrm{m} / \mathrm{s}^{2}\end{array}$ & $\begin{array}{c}\varphi_{\mathrm{c}}(\mathrm{t})_{\max } \\
/ \mathrm{rad}\end{array}$ & $\begin{array}{c}Y_{\mathrm{c}}\left(t_{\mathrm{p}}\right)_{\min } \\
/ \mathrm{m}\end{array}$ & $t_{\mathrm{p}} / \mathrm{s} L_{\mathrm{m}} / \mathrm{m}$ \\
\hline Reference & 20 & & 0.3 & 2.01 & 1.82 & -1.69 & 0.09 & 2.90 & 2.3947 .8 \\
\hline HIL simulation platform & & 5 & & 1.99 & 1.61 & -1.61 & 0.10 & 2.97 & 2.4048 \\
\hline Error $(\%)$ & & & & 1 & 11.5 & 4.7 & 11.1 & 2.4 & $0.4 \quad 0.42$ \\
\hline
\end{tabular}

an $8 \mathrm{DOF}$ vehicle model, without path planning) and a self-driving mode in Trucksim (based on the Macadam model).

The simulations are conducted in a typical lane-change maneuver in $20 \mathrm{~m} / \mathrm{s}$ with $0.3 \mathrm{~Hz}$ steering frequency. Contrasts of the tractor's motions in different lane-change control methods are shown in Figure 9, including trajectory, lateral tracking error, lateral velocity and yaw angle. The lateral tracking error could be limited in $0.02 \mathrm{~m}$, which is better than that of Trucksim. Besides, the yaw angle is very close to the reference, even though without path planning. Importantly, no low-frequency oscillation similar to that controlled by Trucksim [about $0.5 \mathrm{~Hz}$ shown in Figure 9(d)] is observed. Moreover, the lateral velocity is precisely controlled and more stable without any redundant oscillation than that with other methods [Figure 9(e) and (f)]. Thus, the proposed 8DOF model with path planning obtains the least tracking errors with the desired values. The yaw angle controlled by the $8 \mathrm{DOF}$ model without path planning also has good effects. However, there are still prominent defects, such as the slower tracking speed and the larger errors than those of other methods, indicating the importance of preview. Furthermore, low frequency oscillation occurs during steering return. These results indicate that the proposed combined controller has better effects for tracking and robust stability in self-driving modes.

\subsection{Multi-mode on a straight road}

The scenario is simulated as complex traffic with multiple overtaking conducted in different modes to escape with obstacle vehicles ahead, which is designed to test the tracking quality with multi-mode on a straight road. Based on this idea, the presented path planning and control results based on the scenario are displayed in Figure 10.

Figure 10 (a) shows a good consistence of trajectory tracking. When one of the applicable conditions of a lane change is satisfied (Table 2), the host vehicle would be driven in the corresponding self-driving mode. The host vehicle escapes the obstacles by lane change at about 6.44 , 10.22, 13.12 and $15.51 \mathrm{~s}$. The tracking errors in Figure 10 (b) show that the tracking errors in the whole process are less than $0.02 \mathrm{~m}$. The details show that the constant velocity modes (nos. 1, 2 and 3) lead to better tracking compared with the uniform deceleration mode (no. 4). Thus, higher steering frequency corresponds to stronger coupling of longitudinal and lateral motions and larger errors. Besides, Figure 10(c) and 10 (d) indicates that the longitudinal and lateral velocities have good consistency with the references through braking and driving modes. 
The tractor yaw angle and articulated angle showed in Figure $10(\mathrm{e})$ and $10(\mathrm{f})$ are also well controlled, respectively, which demonstrate that the controller has good decouple effects. As shown in Figure $10(\mathrm{~g})$ and $10(\mathrm{~h})$, the control inputs of steering, DYC and longitudinal forces of axles are smooth. The steering angle and forces increase obviously in braking and driving maneuvers, and the maximum longitudinal forces of the tractor and semitrailer axles are, respectively, about 14,490, 21,400 and $11,550 \mathrm{~N}$, which are far from the limit of the tires (respectively, 40,384, 37,282 and 35,222 $\mathrm{N}$ estimated based on the load distribution of each axle). Thus, the vehicle is safe and has good tracking in different modes.

\subsection{Typical modes on the continuous curved road}

To verify the performance of overtaking maneuvers for anticollision, we designed a typical scenario on the continuous curved road, to test the control effects of the presented selfdriving modes. The curved road is composed of three parts with radii of 600,800 and $1,000 \mathrm{~m}$ circular arcs. Two obstacles are ahead in the different lanes of the road. The host vehicle is retained with a constant speed of $20 \mathrm{~m} / \mathrm{s}$ and then emergency steering has a constant frequency of $0.3 \mathrm{~Hz}$ when the distance gap to obstacles ahead is $75 \mathrm{~m}$, which satisfies the condition of Mode 3.

The control results, while overtaking, are shown in Figure 11. Figure 11(a) and 11(b) displayed the global trajectory and the tracking error of the host vehicle, which shows that the absolute error is less than $0.03 \mathrm{~m}$. It demonstrates a good tracking effect with the desired reference. In addition, as shown in Figure 11(c) and 11(d), the curve combined lane change causes the lateral velocity continuous large-scale variety. Besides, longitudinal and lateral velocities are well decoupled and controlled despite small-amplitude longitudinal fluctuations. Figure 11 (e) and 11(f) indicates that the tractor yawrate and articulated angle also have good consistency with the desired references and the absolute values are less than $0.15 \mathrm{rad} / \mathrm{s}$ and $0.01 \mathrm{rad}$, respectively, indicating that the vehicle is stable.

Furthermore, Figure $11(\mathrm{~g})$ and $11(\mathrm{~h})$ shows that the control inputs are continuous and the changing trend of the steering input is consistent with tractor yawrate, larger steering while lane changing than simple cornering, as well as the inputs of direct yaw torque and longitudinal force. The axles' absolute longitudinal forces of the tractor and semitrailer are less than $6,000 \mathrm{~N}$, which are considerably far from reaching the limit of the tire. This result indicates that the vehicle is controlled in an absolute stability in the whole lane-change on the curved road. Therefore, the proposed controller also deals with obstacle avoidance on curved roads.

\subsection{Control model verification by hardware in the loop}

Path-planning model and controller verifications are conducted by a specialized HIL simulation platform. As shown in Figure 12, the HIL platform is built based on the physical system involving steering and braking and software system of virtual test drive, which could provide advanced and professional development tools for ADAS and self-driving vehicles. Figure 12 shows a typical lanechange scenario on a highway involving two-way six lanes, a host-articulated truck, an obstacle vehicle ahead and so on. A self-driving mode and control strategy are embedded in the HIL system to simulate anti-collision by lane change. The vehicle speed and lane change time are set to $20 \mathrm{~m} / \mathrm{s}$ and $3.3 \mathrm{~s}$, respectively. The defining values of the road and vehicle are listed in Table 3 (Table 4 ).

Figure 13(a), 13(b), 13(c) and 13(d) indicates the trends of the semitrailer trajectory and lateral dynamics obtained by the HIL simulation platform with the desired reference. The trajectory of the proposed model is consistent with that of the HIL platform and the lateral velocity as well as acceleration, and the lateral displacement error is less than $0.12 \mathrm{~m}$. Moreover, the root means square errors of the trajectories, lateral velocities and accelerations are about $0.0665,0.0725$ and 0.1569 , respectively. Thus, from both tendencies and values, the proposed models have good control effects and it can provide a feasible reference for self-driving vehicles.

Table 5 shows the contrasts of related parameters, including the maximum of the semitrailer lateral velocity, in addition to the acceleration and critical values for anticollision, minimum safe distance and errors with HIL. The errors of the vehicle's lateral acceleration and yaw angle are more than $10 \%$, still, the key parameters that can characterize vehicle anti-collision, such as critical time and minimum safe distance, are relatively small (i.e. less than $5 \%$ ). Thus, the proposed path planning and control model is sufficiently accurate to analyze vehicle safety lane-change for anti-collision.

\section{Conclusion}

In consideration of the handling difficulties and high degree of danger for self-driving articulated truck making lane-change maneuvers, a novel safe lane-change path planning and control method is proposed, which provides a valuable reference for the quantitative analysis and evaluation of lane-change safety of path planning, decisionmaking and tracking control for the intelligent articulated vehicles. Points of discussion and conclusions can be summarized as follows;

- A double-Gaussian distribution is deduced to describe the lane-change trajectories of a tractor and a semitrailer. The model has successfully converted the two vehicles' lanechanging motions into simple double probability issues and specific parameters are accurately obtained by the self-driving, vehicle dynamics and road characteristics. The results show that the model has the advantage of continuous curvature and simplicity. More importantly, it could clearly depict the intelligent dynamics of the articulated vehicles, especially coupling performance.

- Safe lane-change constraint and minimum distance model are proposed according to the vehicle dynamic and road static allowable conditions. Self-driving decision modes of the articulated vehicle are abstracted and safe lane-change is defined between the host and obstacle. The detailed analysis results provide a principle of designing safe lanechange path planning.

- A combined controller is designed using feedback linearization and preview optimization. In addition, 
vehicle lane changing in typical scenarios is comprehensively tested. And the path-planning model and controller validation are conducted by a specialized HIL simulation platform. The relative results indicate that the combined controller can ensure good tracking and robust stability for the closed-loop nonlinear system.

With the development of intelligent networking technology, smart vehicles and smart roads are areas worthy of further study. From the perspective of the cooperative vehicle-infrastructure system, the following could be considered in the future;

- Path planning is a primary issue for safety and efficient lane changing. Diversified styles of trajectory planning should be defined to improve the self-driving vehicle's adaptability, such as dynamic driving, eco-friendly or neutral. The driving habits and preferences of human drivers, especially for commercial trucks, should be considered.

- Based on advanced theory and big data analysis, decision mechanism and risk assessment should be further studied to achieve good adaptation for complex scenarios, such as multiple vehicles and bad weather.

- Vehicle robustness problem caused by uncertainty of the model and external disturbance should be improved by integrating trajectory tracking into robust algorithm.

- Based on multi-source information fusion, intelligent V2V and V2X, further systematic studies of cooperative optical control and multi-body intelligence for vehicle platoon are urgently needed.

\section{Acknowledgement}

This work is partially supported by the Joint Laboratory for Internet of Vehicles, Ministry of Education - China Mobile Communications Corporation under Project No. ICVKF2018-02, the State Key Laboratory of Automotive Safety and Energy under Project No. KF2013, the National Natural Science Foundation of China No. 51775565, the Tianjin Science and Technology Project (Grant Nos. 16PTGCCX00150, 18YFZCGX00380 and 18ZLZDZF00390), the Tianjin Development and Reform Commission Project (Grant No. TJZNZZ1811), the University Foundation of Tianjin University of Technology and Education (Grant No. KYQD 1710) and the Fundamental Research Funds for the Central Universities (Grant No. 18lgpy83). The first author would like to thank Liu X.L., Fang R., Dr. Zhang R.H., Dr. Pang Y.W. and Tong Y.K. and also Professor Wang J.Q. from School of Vehicle and Mobility in Tsinghua University for valuable discussions to improve the quality and presentation of this paper.

\section{References}

Attia, R., Orjuela, R. and Basset, M. (2012), "Coupled longitudinal and lateral control strategy improving lateral stability for autonomous vehicle", in Proc. American Control Conference, Fairmont Queen Elizabeth, Montréal.

Attia, R., Orjuela, R. and Basset, M. (2014), "Nonlinear cascade strategy for longitudinal control in automated vehicle guidance", Control Engineering Practice, Vol. 29, pp. 225-234.

Benjamin, G., Lutz, G. and Moritz, W. (2016), "Lateral vehicle trajectory optimization using constrained linear timevarying MPC", IEEE Transactions on Intelligent Transportation Systems, Vol. 18 No. 6, pp. 1586-1595.

Cai, J.Y., Jiang, H.B., Chen, L., Liu, J., Cai, Y.F. and Wang, J.Y. (2019), "Implementation and development of a trajectory tracking control system for intelligent vehicle", Fournal of Intelligent \& Robotic Systems, Vol. 94 No. 1, pp. 251-264.

Cao, H.T., Zhao, S., Song, X.L., Bao, S., Li, M.J. and Huang, Z. (2019), "Design and evaluation of a model predictive vehicle control algorithm for automated driving using a vehicle traffic simulator", Vehicle System Dynamics, Vol. 57 No. 9, pp. 1287-1317.

Choe, R., Navarro, J.P., Cichella, V., Xargay, E. and Hovakimyan, N. (2016), "Cooperative trajectory generation using Pythagorean hodograph Bezier curves", foumal of Guidance Control and Dynamics, Vol. 39 No. 8, pp. 1-20.

Devin, C. and Hung, M.L. (2018), "Extended rapidly exploring random tree-based dynamic path planning and replanning for mobile robots", International fournal of Advanced Robotic Systems, Vol. 15 No. 3, pp. 1-15.

Emirler, M.T., Meric, I., Uygan, C., Bilin, A.G. and Levent, G. (2014), "Robust PID steering control in parameter space for highly automated driving", International fournal of Vehicular Technology, Vol. 2014, pp. 1-8.

Fitri, Y., Aminudin, A., Shamsul, S. and Yasuchika, M. (2016), "Study of model predictive control for pathfollowing autonomous ground vehicle control under crosswind effect", Fournal of Control Science and Engineering, doi: 10.1155/2016/6752671.

Francis, B., Elliott, A. and Weldon, M. (2016), "Smoothing group-based trajectory models through B-splines", Fournal of Developmental and Life-Course Criminology, Vol. 2 No. 1, pp. 113-133.

Hitay, O. (2019), Introduction to Feedback Control Theory, CRC Press, Inc.

Jonathan, J.R., Shirley, R., Salissou, M. and Aidan, F. (2018), "What are the factors that contribute to road accidents? An assessment of law enforcement views, ordinary drivers' opinions, and road accident records", Accident Analysis and Prevention, No. 115, pp. 11-24.

Lim, W., Lee, S., Sunwoo, M. and Jo, K. (2018), "Hierarchical trajectory planning of an autonomous car based on the integration of a sampling and an optimization method", IEEE Transactions on Intelligent Transportation Systems, Vol. 19 No. 2, pp. 613-626.

Litman, T. (2015), "Autonomous vehicle implementation predictions: implications for transport planning", Transportation Research Board Annual Meeting, pp. 36-42.

Ma, W.S., Chen, K. and Ding, L. (2015), "Trajectory optimization of maypole braiding machine carrier", Mathematical Models in Engineering, Vol. 1 No. 2, pp. 72-82.

Macadam, C.C. (1980), “An optimal preview control for linear systems", Fournal of Dynamic Systems, Measurement, and Control, Vol. 102 No. 3, pp. 188-190.

Ni, A.V. and Park, C.W. (2017), "Finding analytic solutions on active arcs of the optimal trajectory in a gravitational field 
and their applications", Automation and Remote Control, Vol. 78 No. 2, pp. 313-331.

Nurbaiti, W., Hairi, Z., Mohd, A.A.R., Satoshi, K. and Pongsathom, R. (2017), "Study on potential field based motion planning and control for automated vehicle collision avoidance systems", IEEE International Conference on Mechatronics (ICM), doi: 10.1109/ ICMECH.2017.7921105.

Peng, T., Guan, Z.W., Zhang, R.H., Dong, J.S., Li, K.N. and Xu, H.G. (2017), "Bifurcation of lane change and control on highway for tractor-semitrailer under rainy weather", fournal of Advanced Transportation, Vol. 2017 No. 3, pp. 1-19.

Peng, T., Su, L.L., Zhang, R.H., Guan, Z.W., Zhao, H.L., Qiu, Z.J., Zong, C.F. and Xu, H.G. (2019), “A new safe lane-change trajectory model and collision avoidance control method for automatic driving vehicles", Expert Systems with Applications, Vol. 141, doi: 10.1016/j.eswa.2019.112953.

Public Security Traffic Management Department (2017), "Statistical annual report of road traffic accidents of China", Traffic Management Science Research Institute of the Ministry of Public Security, pp. 1-5.

Qureshi, A.H. and Ayaz, Y. (2015), "Intelligent bidirectional rapidly-exploring random trees for optimal motion planning in complex cluttered environments", Robotics and Autonomous Systems, Vol. 68, pp. 1-11.

Simba, K.R., Uchiyama, N. and Sano, S. (2016), "Real-time smooth trajectory generation for nonholonomic mobile robots using Bezier curves", Robotics and Computer-Integrated Manufacturing, Vol. 41, pp. 31-42.

Sun, X.J., Zhang, H., Meng, W.J., Zhang, R.H., Li, K.N. and Peng, T. (2018), "Primary resonance analysis and vibration suppression for the harmonically excited nonlinear suspension system using a pair of symmetric viscoelastic buffers", Nonlinear Dynamics, Vol. 94 No. 2, pp. 1243-1265.
Trang, P., Truyen, T., Dinh, P. and Svetha, V. (2017), "Predicting healthcare trajectories from medical records: a deep learning approach", Fournal of Biomedical Informatics, Vol. 69, pp. 218-229.

Xiong, H.Y., Zhu, X.L. and Zhang, R.H. (2018), "Energy recovery strategy numerical simulation for dual axle drive pure electric vehicle based on motor loss model and big data calculation", Complexity, Vol. 2018 No. 22, pp. 1-14.

You, F., Zhang, R.H., Guo, L., et al. (2015), "Trajectory planning and tracking control for autonomous lane change maneuver based on the cooperative vehicle infrastructure system", Expert Systems with Applications, Vol. 42 No. 14, pp. 5932-5946.

Zhang, R.H., Peng, T., Lv, Z.H. and Qiu, Z.J. (2020), "Bifurcation and robust control analysis to tractorsemitrailer with interference on rainy slippery road", Future Generation Computer Systems, Vol. 107, pp. 126-143.

Zhang, R.H., He, Z.C., Wang, H.W., You, F. and Li, K.N. (2017), "Study on self-tuning tyre friction control for developing main-servo loop integrated chassis control system”, IEEE Access, Vol. 5, pp. 6649-6660.

\section{Further reading}

Kumar, M.K. and Prasad, V.K. (2015), "Driver behavior analysis and prediction models: a survey", International Fournal of Computer Science and Information Technologies, Vol. 6 No. 4, pp. 3328-3333.

Peng, T., Guan, Z.W., Zhang, R.H., Du, F., Zong, C.F. and Li, K.N. (2018), "Stability region estimation of lane change on highway for tractor-semitrailer", fournal of Traffic and Transportation Engineering, Vol. 18 No. 4, pp. 90-102. 


\section{Appendix 1}

\section{Lane-change trajectory model}

According to equation (2), the lateral accelerations of the vehicles could be obtained by derivation, represented as:

$$
\left\{\begin{array}{l}
a_{Y \mathrm{t}}\left(t_{i}\right)=\frac{-d}{\sqrt{2 \pi} \sigma_{y \mathrm{t}}^{3}} \exp \left(\frac{-\left(t_{i}-\mu_{y}\right)^{2}}{2 \sigma_{y \mathrm{t}}^{2}}\right)\left(t_{i}-\mu_{y}\right) \\
a_{Y \mathrm{~s}}\left(t_{i}\right)=\frac{-d}{\sqrt{2 \pi} \sigma_{y \mathrm{~s}}^{3}} \exp \left(\frac{-\left(t_{i}-\mu_{y}-\Delta t\right)^{2}}{2 \sigma_{y \mathrm{t}}^{2}}\right)\left(t_{i}-\mu_{y}-\Delta t_{i}\right)
\end{array}\right.
$$

where $a_{Y \mathrm{t}}$ and $a_{Y \mathrm{~s}}$ are, respectively, the lateral accelerations of the tractor and the semitrailer.

The displacements of the vehicles could be deduced by integration, as follows:

$$
\left\{\begin{array}{l}
Y_{\mathrm{t}}=\int_{0}^{T_{\mathrm{t}}} \frac{d}{\sqrt{2 \pi} \sigma_{y \mathrm{t}}} \exp \left(\frac{-\left(t_{i}-\mu_{y}\right)^{2}}{2 \sigma_{y \mathrm{t}}^{2}}\right) d t \\
Y_{\mathrm{s}}=\int_{0}^{T_{\mathrm{s}}} \frac{d}{\sqrt{2 \pi} \sigma_{y \mathrm{~s}}} \exp \left(\frac{-\left(t_{i}-\mu_{y}-\Delta t_{i}\right)^{2}}{2 \sigma_{y \mathrm{~s}}^{2}}\right) d t
\end{array}\right.
$$

where $Y_{\mathrm{t}}$ and $T_{\mathrm{t}}$ are the lateral displacement and lane-change time of the tractor, respectively. $Y_{\mathrm{s}}$ and $T_{\mathrm{s}}$ are the parameters of the semitrailer. $T_{\mathrm{t}}$ and $T_{\mathrm{s}}$ could be treated as the sinusoidal steering cycles.

Then, the maximum values of the vehicles' lateral dynamic parameters could be obtained as follows:

$$
\begin{aligned}
& \left\{\begin{array}{l}
V_{Y \mathrm{t}}\left(t_{i}\right)_{\max }=V_{Y \mathrm{t}}\left(\mu_{y}\right)=\frac{d}{\sqrt{2 \pi} \sigma_{y \mathrm{t}}}, t_{i}=\mu_{y} \\
V_{Y \mathrm{~s}}\left(t_{i}\right)_{\max }=V_{Y \mathrm{~s}}\left(\mu_{y}+\Delta t_{i}\right)=\frac{d}{\sqrt{2 \pi} \sigma_{y \mathrm{~s}}}, t_{i}=\mu_{y}+\Delta t_{i}
\end{array}\right. \\
& \left\{\begin{array}{l}
\left|a_{Y \mathrm{t}}\left(t_{i}\right)_{\max }\right|=\frac{d}{\sqrt{2 \pi} \sigma_{y \mathrm{t}}^{2}} \exp \left(-\frac{1}{2}\right), t_{i}= \pm \sigma_{y \mathrm{t}}+\mu_{y} \\
\left|a_{Y \mathrm{~s}}\left(t_{i}\right)_{\max }\right|=\frac{d}{\sqrt{2 \pi} \sigma_{y \mathrm{~s}}^{2}} \exp \left(-\frac{1}{2}\right), t_{i}= \pm \sigma_{y \mathrm{t}}+\mu_{y}+\Delta t_{i}
\end{array}\right.
\end{aligned}
$$

Moreover, given that the lateral displacement is constant with none lateral velocity while lane-change finishing, the maximum values of lateral displacements in lane change are equal to $d$, as follows:

$$
\left\{\begin{aligned}
Y_{\mathrm{t} \max } & =d \frac{1}{\sqrt{2 \pi} \sigma_{y \mathrm{t}}} \int_{-\infty}^{+\infty} \exp \left(\frac{-\left(t_{i}-\mu_{y}\right)^{2}}{2 \sigma_{y \mathrm{t}}^{2}}\right) d t \\
& =d \\
Y_{\mathrm{s} \max } & =d \frac{1}{\sqrt{2 \pi} \sigma_{y \mathrm{~s}}} \int_{-\infty}^{+\infty} \exp \left(\frac{-\left(t_{i}-\mu_{y}-\Delta t_{i}\right)^{2}}{2 \sigma_{y \mathrm{~s}}^{2}}\right) d t \\
& =d
\end{aligned}\right.
$$




\section{Appendix 2}

\section{Relevant symbols and parameters of the vehicle model}

According to Newton's second law and force moment balance, the $8 \mathrm{DOF}$ vehicle mechanical equilibrium is represented as:

$$
\begin{aligned}
& f(\boldsymbol{X})=\left\{\begin{array}{l}
a_{11} F_{y f}+a_{12} F_{y \mathrm{r}}+a_{13} F_{y \mathrm{~s}} \\
a_{21} F_{y \mathrm{f}}+a_{22} F_{y \mathrm{r}}+a_{23} F_{y \mathrm{~s}} \\
a_{31} F_{\mathrm{yf}}+a_{32} F_{y \mathrm{r}}+a_{33} F_{y \mathrm{~s}} \\
x_{3} \\
a_{51} F_{y \mathrm{f}}+a_{52} F_{y \mathrm{r}}+a_{53} F_{y \mathrm{~s}} \\
x_{5} \\
a_{71} F_{y f} \\
a_{81} F_{y \mathrm{r}} \\
a_{91} F_{y \mathrm{~s}} \\
-\frac{C_{\mathrm{w}} x_{7}}{I_{\mathrm{w}}}-\frac{K_{\mathrm{w}} x_{8}}{I_{\mathrm{w}}}-\frac{\varepsilon F_{y \mathrm{f}}}{I_{\mathrm{w}}}
\end{array}\right. \\
& \mathrm{g}(\boldsymbol{X})=\left[\boldsymbol{g}_{1}, \boldsymbol{g}_{2}, \boldsymbol{g}_{3}, \mathbf{g}_{4}, \boldsymbol{g}_{5}\right] \\
& \mathbf{u}=\left[\begin{array}{lllll}
u_{1} & u_{2} & u_{3} & u_{4} & u_{5}
\end{array}\right]^{\mathrm{T}} \\
& =\left[\begin{array}{lllll}
F_{x \mathrm{fc}} & F_{\mathrm{xrc}} & F_{\mathrm{xsc}} & M_{\mathrm{c}} & \delta_{\text {swc }}
\end{array}\right]^{\mathrm{T}}
\end{aligned}
$$

where

$$
\begin{gathered}
a_{11}=a_{12}=a_{13}=-1 /\left(m_{\mathrm{t}}+m_{\mathrm{s}}\right) \\
a_{21}=\left[\left(a_{\mathrm{s}}^{2} m_{\mathrm{t}}-I_{z \mathrm{~s}}\right) I_{z \mathrm{t}} m_{\mathrm{s}}+\left(c+a_{\mathrm{t}}\right) c I_{z \mathrm{~s}} m_{\mathrm{t}} m_{\mathrm{s}}\right] /\left(m_{\mathrm{t}} S\right) \\
a_{22}=\left[\left(a_{\mathrm{s}}^{2} I_{z \mathrm{t}}+c^{2} I_{z \mathrm{~s}}\right) m_{\mathrm{s}}+\left(I_{z \mathrm{t}}-b_{\mathrm{t}} c m_{\mathrm{s}}\right) I_{z \mathrm{~s}}\right] / S \\
a_{23}=-I_{z \mathrm{t}}\left(a_{\mathrm{s}} b_{\mathrm{s}} m_{\mathrm{s}}-I_{z \mathrm{~s}}\right) / S \\
a_{31}=\left[\left(a_{\mathrm{t}} m_{\mathrm{t}}+a_{\mathrm{t}} m_{\mathrm{s}}+c m_{\mathrm{s}}\right) I_{z \mathrm{~s}}+a_{\mathrm{t}} a_{\mathrm{s}}^{2} m_{\mathrm{t}} m_{\mathrm{s}}\right] / S \\
a_{32}=\left[c m_{\mathrm{s}} I_{z \mathrm{~s}}-b_{\mathrm{t}}\left(m_{\mathrm{t}}+m_{\mathrm{s}}\right) I_{z \mathrm{~s}}-b_{\mathrm{t}} a_{\mathrm{s}}^{2} m_{\mathrm{t}} m_{\mathrm{s}}\right] / S \\
a_{33}=\left(a_{\mathrm{s}} c b_{\mathrm{s}} m_{\mathrm{t}} m_{\mathrm{s}}-c m_{\mathrm{s}} I_{z \mathrm{t}}\right) / S \\
a_{51}=\left[a_{\mathrm{s}} I_{z \mathrm{t}}\left(m_{\mathrm{t}}+m_{\mathrm{s}}\right)+m_{\mathrm{s}}\left(c I_{z \mathrm{~s}}+a_{\mathrm{s}} I_{z \mathrm{t}}\right)\right] / S \\
a_{52}=\left[\left(c I_{z \mathrm{~s}}-a_{\mathrm{s}} I_{z \mathrm{t}}\right) m_{\mathrm{s}}-b_{\mathrm{t}} I_{z \mathrm{~s}}\left(m_{\mathrm{t}}+m_{\mathrm{s}}\right)\right] / S \\
a_{53}=\left[\left(a_{\mathrm{s}}+c\right) c b_{\mathrm{s}} m_{\mathrm{t}} m_{\mathrm{s}}+\left(a_{\mathrm{s}}+b_{\mathrm{s}}\right) I_{z \mathrm{t}} m_{\mathrm{t}}\right] / S
\end{gathered}
$$

$$
a_{71}=a_{81}=a_{91}=-r_{\mathrm{w}} / \mathcal{f}_{\mathrm{w}}
$$$$
S=\left(a_{\mathrm{s}}^{2} I_{z \mathrm{t}}+c^{2} I_{z \mathrm{~s}}\right) m_{\mathrm{t}} m_{\mathrm{s}}+\left(m_{\mathrm{t}}+m_{\mathrm{s}}\right) I_{z \mathrm{t}} I_{z \mathrm{~s}}
$$$$
\boldsymbol{g}_{1}=\left[\begin{array}{lllll}
-a_{11} \cos \left(x_{4}+x_{11}\right) & -a_{12} \cos x_{4} & 0 & 0 & -a_{13} \cos \left(x_{4}-x_{6}\right)
\end{array}\right]
$$

$$
g_{1}=\left[\begin{array}{c}
-a_{11} \cos \left(x_{4}+x_{11}\right) \\
a_{21} \sin \left(x_{4}+x_{11}\right) \\
a_{31} \sin \left(x_{4}+x_{11}\right) \\
0 \\
a_{51} \sin \left(x_{4}+x_{11}\right) \\
0 \\
\frac{r_{\mathrm{W}}}{\mathcal{F}_{\mathrm{w}}} \cos \left(x_{4}+x_{11}\right) \\
0 \\
0 \\
0 \\
0
\end{array}\right] \mathrm{g}_{2}=\left[\begin{array}{c}
-a_{12} \cos x_{4} \\
a_{22} \sin x_{4} \\
a_{32} \sin x_{4} \\
0 \\
a_{52} \sin x_{4} \\
0 \\
0 \\
\frac{r_{\mathrm{W}}}{\mathcal{F}_{\mathrm{w}}} \cos x_{4} \\
0 \\
0 \\
0
\end{array}\right] ;
$$

$$
g_{3}=\left[\begin{array}{c}
-a_{13} \cos \left(x_{4}-x_{6}\right) \\
a_{23} \sin \left(x_{4}-x_{6}\right) \\
a_{33} \sin \left(x_{4}-x_{6}\right) \\
0 \\
a_{53} \sin \left(x_{4}-x_{6}\right) \\
0 \\
0 \\
0 \\
\frac{r_{\mathrm{w}}}{\mathcal{F}_{\mathrm{w}}} \cos \left(x_{4}-x_{6}\right) \\
0 \\
0
\end{array}\right]
$$$$
\mathbf{g}_{4}=\left[\begin{array}{c}
0 \\
\left(c I_{z \mathrm{~s}}-a_{\mathrm{s}} I_{z \mathrm{t}}\right) m_{\mathrm{s}} / S \\
0 \\
0 a_{\mathrm{s}}\left(a_{\mathrm{s}}+c\right) m_{\mathrm{t}} m_{\mathrm{s}}+\left(m_{\mathrm{s}}+I_{z \mathrm{~s}}\right] / S \\
{\left[a_{\mathrm{s}}\left(a_{\mathrm{s}}+2 c\right) m_{\mathrm{t}} m_{\mathrm{s}}+\left(m_{\mathrm{t}}+m_{\mathrm{s}}\right)\left(I_{z \mathrm{t}}+I_{z \mathrm{~s}}\right)\right] / S} \\
0 \\
0 \\
0 \\
0 \\
0
\end{array}\right]
$$

$$
\boldsymbol{g}_{5}=\left[\begin{array}{c}
0 \\
0 \\
0 \\
0 \\
0 \\
0 \\
0 \\
0 \\
0 \\
k_{\mathrm{w}} \\
i I_{\mathrm{w}} \\
0
\end{array}\right]
$$


Table A1 Vehicle model parameters and symbols

\begin{tabular}{|c|c|c|c|}
\hline Symbol & Parameter name & Value & Unit \\
\hline$m_{\mathrm{t}}$ & Tractor mass & 8,500 & $\mathrm{~kg}$ \\
\hline$m_{\mathrm{s}}$ & Semitrailer mass & 7,600 & $\mathrm{~kg}$ \\
\hline$a_{\mathrm{t}}$ & Distance from tractor's centriod to front axle & 1.8 & $\mathrm{~m}$ \\
\hline$b_{\mathrm{t}}$ & Distance from tractor's centriod to rear axle & 2.1 & $\mathrm{~m}$ \\
\hline$c$ & Distance from tractor's centriod to articulated point & 1.8 & $\mathrm{~m}$ \\
\hline$a_{s}$ & Distance from semitrailer's centriod to articulated point & 5.05 & $\mathrm{~m}$ \\
\hline$b_{\mathrm{s}}$ & Distance from semitrailer's centriod to rear axle & 2.9 & $\mathrm{~m}$ \\
\hline$l_{z t}$ & Tractor's yaw moment of inertia & 35,100 & $\mathrm{kgm}^{2}$ \\
\hline$I_{z s}$ & Semitrailer's yaw moment of inertia & 107,800 & $\mathrm{kgm}^{2}$ \\
\hline$J_{w}$ & Wheel moment of inertia & 0.4 & $\mathrm{kgm}^{2}$ \\
\hline$r_{\mathrm{w}}$ & Wheel radius & 0.505 & $\mathrm{~m}$ \\
\hline$I_{\mathrm{w}}$ & Moment of inertia of steering wheel around spin & 10 & $\mathrm{kgm}^{2}$ \\
\hline$C_{\mathrm{w}}$ & Damping coefficient of steering wheel around spin & 60 & - \\
\hline$K_{\mathrm{w}}$ & Steering system stiffness & 2,000 & $\mathrm{kgm}^{2}$ \\
\hline$\varepsilon$ & Tractor front tire pneumatic trail & 0.01 & $\mathrm{~m}$ \\
\hline$\delta_{\mathrm{f}}$ & Front wheel steering angle of tractor & - & rad \\
\hline$\varphi_{\mathrm{t}}$ & Tractor yaw angle & - & $\mathrm{rad} / \mathrm{s}$ \\
\hline$\varphi_{\mathrm{s}}$ & Semitrailer yaw angle & - & $\mathrm{rad} / \mathrm{s}$ \\
\hline$\theta$ & Articulated angle & - & $\mathrm{rad}$ \\
\hline$\omega_{\mathrm{wf}(\mathrm{r})}$ & Front (rear) wheels' rolling angular velocity of tractor & - & $\mathrm{rad} / \mathrm{s}$ \\
\hline$\omega_{\mathrm{s}}$ & Wheels' rolling angular velocity of semitrailer & - & $\mathrm{rad} / \mathrm{s}$ \\
\hline$u_{\mathrm{wf}(\mathrm{r})}$ & Tractor's velocities of front and rear wheels' centers & - & $\mathrm{m} / \mathrm{s}$ \\
\hline$u_{\text {ws }}$ & Semitrailer's velocities of wheels' centers & - & $\mathrm{m} / \mathrm{s}$ \\
\hline$F_{y f(r)}$ & Front (rear) wheels' lateral force of tractor & - & $\mathrm{N}$ \\
\hline$F_{y s}$ & Wheels' lateral force of semitrailer & - & $\mathrm{N}$ \\
\hline$F_{x f c}$ & Tractor's front axle longitudinal driving force by controller & - & $\mathrm{N}$ \\
\hline$F_{x \mathrm{rc}}$ & Tractor's rear axle longitudinal driving force by controller & - & $\mathrm{N}$ \\
\hline$F_{x s c}$ & Semitrailer's axle longitudinal driving force by controller & - & $\mathrm{N}$ \\
\hline$M_{\mathrm{c}}$ & Yaw moment by controller & - & $\mathrm{Nm}$ \\
\hline$\delta_{\text {swc }}$ & Steering wheel angle by controller & - & rad \\
\hline
\end{tabular}

In addition, to support the vehicle steering dynamics, the tires provide the longitudinal and lateral forces necessary to change the speed and direction of the vehicle. According to equation (A2-4), Pacejka model is introduced to calculate the tires' longitudinal and lateral forces based on the slip parameters, such as slip ratio and angle, respectively.

$$
\left\{\begin{array}{l}
F_{x}=D_{x} \sin \left(C_{x} \arctan \left\{B_{x} \kappa-E_{x}\left[B_{x} \kappa-\arctan \left(B_{x} \kappa\right)\right]\right\}\right) \\
F_{y}=D_{y} \sin \left(C_{y} \arctan \left\{B_{y} \alpha-E_{y}\left[B_{y} \alpha-\arctan \left(B_{y} \alpha\right)\right]\right\}\right)
\end{array}\right.
$$

where $\mathrm{K}$ is the wheel slip radio, $\alpha$ is the wheel slip angle and there are related fitting coefficients forces $B_{x}, C_{x}, D_{x}$, $E_{x}$ and $B_{y}, C_{y}, D_{y}, E_{y}$, which are usually obtained by test data. The wheels' slip parameters are defined as:

$$
\left\{\begin{array}{l}
\kappa_{\mathrm{f}}=\frac{u_{\mathrm{wf}}-r_{\mathrm{w}} \omega_{\mathrm{wf}}}{u_{\mathrm{wf}}} \times 100 \% \\
\kappa_{\mathrm{r}}=\frac{u_{\mathrm{wr}}-r_{\mathrm{w}} \omega_{\mathrm{wr}}}{u_{\mathrm{wr}}} \times 100 \% \\
\kappa_{\mathrm{s}}=\frac{u_{\mathrm{ws}}-r_{\mathrm{w}} \omega_{\mathrm{ws}}}{u_{\mathrm{ws}}} \times 100 \% \\
\alpha_{\mathrm{f}}=\frac{\dot{Y}_{\mathrm{t}}}{\dot{X}_{\mathrm{t}}}+\frac{a_{\mathrm{t}} \phi_{\mathrm{t}}}{\dot{X}_{\mathrm{t}}}-\varphi_{\mathrm{t}}-\delta_{\mathrm{f}} \\
\alpha_{\mathrm{r}}=\frac{\dot{Y}_{\mathrm{t}}}{\dot{X}_{\mathrm{t}}}-\frac{b_{\mathrm{t}} \phi_{\mathrm{t}}}{\dot{X}_{\mathrm{t}}}-\varphi_{\mathrm{t}} \\
\alpha_{\mathrm{s}}=\frac{\dot{Y}_{\mathrm{s}}}{\dot{X}_{\mathrm{s}}}-\frac{b_{\mathrm{s}} \phi_{\mathrm{s}}}{\dot{X}_{\mathrm{s}}}-\varphi_{\mathrm{s}}
\end{array}\right.
$$

where $u_{\mathrm{wf}}, u_{\mathrm{wr}}$ and $u_{\mathrm{ws}}$ are the velocities of the wheels' center. $\kappa_{\mathrm{f}}, \kappa_{\mathrm{r}}$ and $\kappa_{\mathrm{s}}$ are the wheels' slip radios and $\alpha_{\mathrm{f}}, \alpha_{\mathrm{r}}$, and $\alpha_{\mathrm{s}}$ are the wheels' slip angles of the tractor and the semitrailer.

Relevant vehicle parameters and symbols are listed in Table A1.

\section{Corresponding author}

Tao Peng can be contacted at: pengtao0709@sina.cn

For instructions on how to order reprints of this article, please visit our website:

www.emeraldgrouppublishing.com/licensing/reprints.htm

Or contact us for further details: permissions@emeraldinsight.com 